\title{
Approximation of Engine Casing Temperature Constraints for Casing Mounted Electronics
}

\author{
Jonathan Kratz ${ }^{1}$ and Dennis Culley ${ }^{2}$ \\ NASA Glenn Research Center, Cleveland, Ohio, 44135, USA \\ and \\ Jeffryes Chapman ${ }^{3}$ \\ Vantage Partners, LLC, Cleveland, OH, 44135, USA
}

\begin{abstract}
The performance of propulsion engine systems is sensitive to weight and volume considerations. This can severely constrain the configuration and complexity of the control system hardware. Distributed Engine Control technology is a response to these concerns by providing more flexibility in designing the control system, and by extension, more functionality leading to higher performing engine systems. Consequently, there can be a weight benefit to mounting modular electronic hardware on the engine core casing in a high temperature environment. This paper attempts to quantify the in-flight temperature constraints for engine casing mounted electronics. In addition, an attempt is made at studying heat soak back effects. The Commercial Modular Aero Propulsion System Simulation 40k (C-MAPSS40k) software is leveraged with real flight data as the inputs to the simulation. A two-dimensional (2-D) heat transfer model is integrated with the engine simulation to approximate the temperature along the length of the engine casing. This modification to the existing C-MAPSS40k software will provide tools and methodologies to develop a better understanding of the requirements for the embedded electronics hardware in future engine systems. Results of the simulations are presented and their implications on temperature constraints for engine casing mounted electronics is discussed.
\end{abstract}

\section{Nomenclature}

\begin{tabular}{|c|c|c|}
\hline$a$ & - & shane coefficient \\
\hline CFD & $=$ & Computational Fluid Dynamics \\
\hline C-MAPSS40k & $=$ & Commercial Modular Aero Propulsion System Simulation \\
\hline$C_{p}$ & $=$ & specific heat \\
\hline dTamb & $=$ & difference between the actual ambient temperature and the standard ambient temperature \\
\hline DEC & $=$ & Distributed Engine Control \\
\hline FADEC & $=$ & Full-Authority Digital Engine Controller \\
\hline FDM & $=$ & Finite Difference Method \\
\hline$h$ & $=$ & convective heat transfer coefficient \\
\hline HPC & $=$ & high pressure compressor \\
\hline HPT & $=$ & high pressure turbine \\
\hline$k_{\text {eff }}$ & $=$ & effective thermal conductivity of a free convecting fluid if it were static \\
\hline$k$ & $=$ & thermal conductivity \\
\hline$l$ & $=$ & distance between nodes of neighboring structural members \\
\hline LPC & $=$ & low pressure compressor \\
\hline LPT & $=$ & low pressure turbine \\
\hline$\dot{m}$ & $=$ & mass flow rate \\
\hline
\end{tabular}

\footnotetext{
${ }^{1}$ Research Engineer, 21000 Brookpark Rd., Cleveland OH, MS-77-1, AIAA Member.

${ }^{2}$ Research Engineer, 21000 Brookpark Rd., Cleveland OH, MS-77-1, Senior AIAA Member.

${ }^{3}$ Aerospace Engineer, 3000 Aerospace Parkway, Brookpark OH, AIAA Member.
} 


$\begin{array}{ll}N & =\text { total number of interior nodes (not including surface nodes) } \\ N u & =\text { Nusselt number } \\ P & =\text { Pressure } \\ \mathrm{PD} & =\text { Present Day } \\ P L A & =\text { Power Lever Angle } \\ Q & =\text { heat transfer } \\ q & =\text { radius } \\ R & =\text { Silicon Carbide } \\ \mathrm{SiC} & =\text { Silicon-on-Insulator } \\ \mathrm{SOI} & =\text { temperature } \\ T & =\text { time } \\ t & =\text { radiation heat transfer coefficient } \\ u & =\text { time step of the discrete solver } \\ \Delta t & =\text { distance into the wall along the radial direction } \\ x & =\text { spatial step in x-direction of the discrete solver } \\ \Delta x & \end{array}$
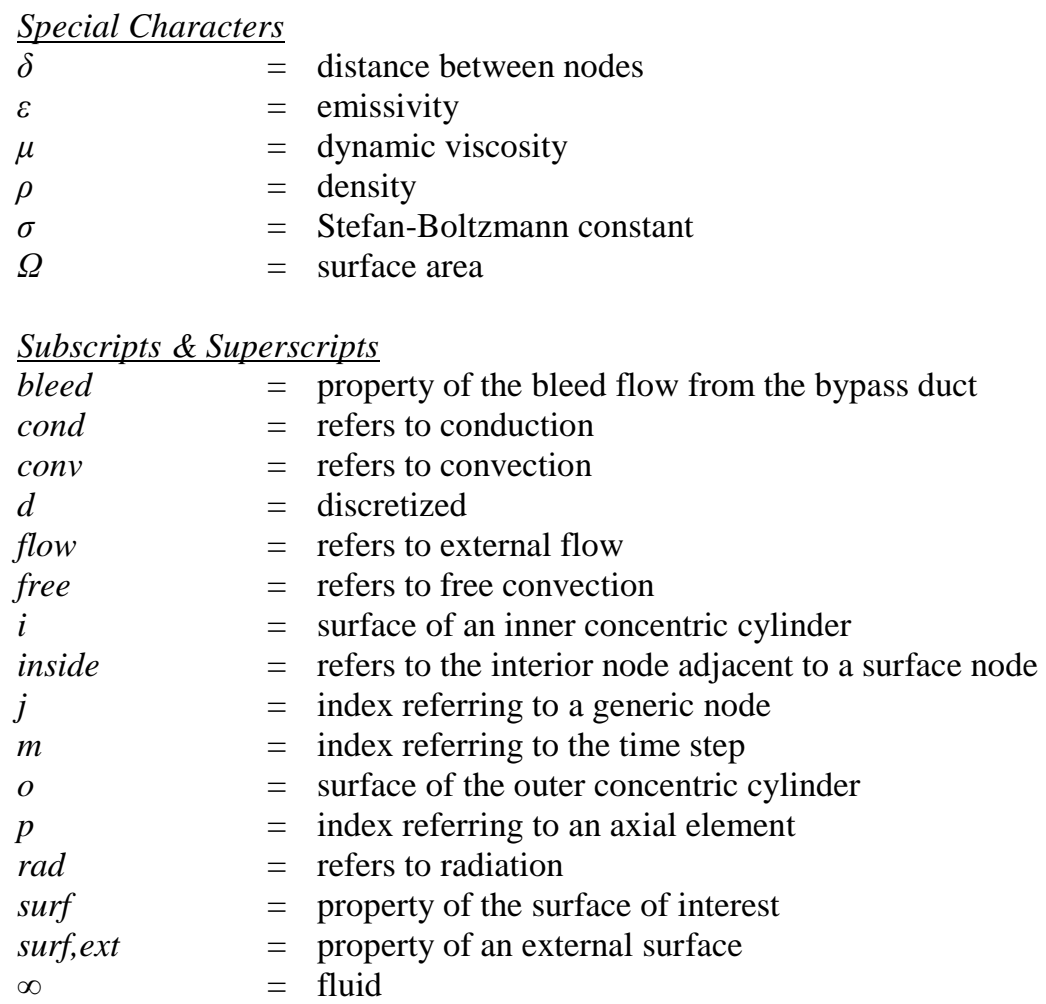

\section{Introduction}

COR a generation, Full Authority Digital Engine Control (FADEC) has been the standard for most gas turbine engine applications. FADEC is a flexible software-driven strategy that integrates control operations across the entire engine system. Its function is reliant on the capability of electronics, and therefore its optimum implementation strategy has been a centralized hardware architecture designed to protect the digital and analog electronics with minimum weight and volume impact ${ }^{1}$. Distributed Engine Control (DEC) is a revolutionary change in the way control hardware is implemented on these engines. DEC provides the FADEC functionality using a flexible hardware-driven strategy that reduces system constraints on controls as well as the engine system. Specifically the engine control system is modularized by distributing some duties of the FADEC across the engine to electronic devices referred to as smart nodes. These devices may include smart sensors and actuators which alleviate the FADEC's workload by taking the responsibility of performing tasks such as analog to digital signal conversion, digital to analog signal conversion, signal conditioning, and in some instances local loop closure. Key to the DEC 
technology are high temperature electronics embedded on the engine core that allow transducer elements to act as intelligent modular devices with digital data interfaces (smart nodes). More information about the concept of DEC technology is provided in Ref. 1.

In the near term, DEC technology provides aerodynamic and thermodynamic engine system benefits, but it also improves engine life cycle cost and can reduce the total system weight ${ }^{1}$. For example, DEC hardware can be more easily located or configured to reduce engine drag by shrinking the size of the FADEC mounted to the fan casing; high temperature electronics can improve heat quality for more efficient cooling while they are also located more easily on the engine; and reusable modular components can reduce design and manufacturing costs. In the long term, assuming the continued advancements in electronics, tremendous new control-based capabilities will be introduced that make significant contributions to engine performance, efficiency, and safety. For example, embedded signal processing can extract new information from each existing sensor location while more rapid control design can improve the accuracy and capabilities of the supervisory system control. Additional benefits to the DEC approach are discussed in Refs. 1, 2, 3, 4, and 5.

The temperature environment on the engine will always be a concern even with high temperature electronics capability for embedded devices. For example, the state of the art materials technology for internal gas path components in the engine is approaching $1500^{\circ} \mathrm{C}^{6}$, however, no known electronics technology can reliably operate under such conditions. Common consumer silicon electronics are typically capable of less than $70^{\circ} \mathrm{C}$ operation while some versions are designed for temperatures up to $150^{\circ} \mathrm{C}^{7}$. Other electronics technologies such as silicon on insulator (SOI) circuits have been known to operate in temperatures up to $300^{\circ} \mathrm{C}^{7}$. Wide band gap electronics such as silicon carbide $(\mathrm{SiC})$ have been demonstrated to operate in temperatures of $500^{\circ} \mathrm{C}$ or more $e^{8,9,10,11,12}$. In all cases, there is an inverse relationship between temperature and electronics reliability. Additionally, the assembly level packaging must compensate for any deficiency in temperature capability and reliability. Clearly, electronics temperature capability has an impact on weight as well as safety aspects at the vehicle level.

Useful information for electronic manufacturers of engine control system components may be anything pertaining to the following questions: (1) What temperature environment will the smart node have to withstand? (i.e. what is the temperature at the mounting location and how quickly and frequently does it change?) and (2) Where can a given smart node be placed to meet temperature and reliability requirements? Most of the smart node components are expected to be mounted to the outer surface of the engine casing (see Fig. 1); therefore it is of interest to quantify the temperature environment of this area.

Characterizing the temperature environment of the engine casing is not a very well documented problem in the literature. Ref. 3 provides a high level estimate with no details as to how it was obtained. Ref. 13 and 14 touch on this topic as well. Ref. 13 uses a 2-D finite element approach, ignoring axial variations, to quantify the temperature of the engine casing for use in determining thermal strains on the casing structure for land-based gas turbine engines. The model does so without consideration of radiation effects. Futhermore, the temperature outside of the casing was assumed to be close to room temperature because land-based power generating turbines were the focus. This is not the case with aero engines. Land-based gas turbine engines have casings that are made of different materials and thicknesses than aero engine casings. Furthermore, only steady state operation is considered for a single axial location on the engine and only for a single operating point. These observations reveal that the results of Ref. 13 are not applicable to aero engines and their vast range of potential operating conditions. Ref. 14 aims to predict engine casing temperature for fighter aircraft, specifically for infrared signature studies and focuses on steady-state analysis only. Once again, its methods and results are not applicable to this kind of analysis.

This paper documents the development of a generic dynamic model to estimate the engine casing surface temperature along its length in order to get a rough idea about potential mounting locations for smart nodes. A simplified approach has been developed in an attempt to estimate the maximum engine casing temperature and dynamic temperature response along the length of the engine. At the center of the approach is a 2-D finite difference method (FDM) scheme for the solid elements with boundary conditions that account for forced and free convection, radiation, and conduction. Heat transfer within the interior cavity (see Fig. 1) is treated with an energy balance method during engine operation and heat transfer properties within all flow paths are approximated using empirical correlations. The model is driven by the outputs of a dynamic simulation of the Commercial Modular AeroPropulsion System Simulation 40k (C-MAPSS40k), a 0-D high fidelity simulation of a generic twin-spool turbofan engine $^{15}$; with a flight profile constructed using real mission data ${ }^{16}$ to provide analysis of the engine casing temperature during in-flight operation. A post flight simulation is also conducted in an attempt to study the effects of thermal transients after shutdown, which characterize the heat soak back for the engine. Based on the simulation results some observations are made concerning temperature requirements for engine casing mounted smart nodes. It should be kept in mind throughout the results analysis that this is an engine specific problem and numerous simplifications and assumptions were necessary for this application. Therefore the main take away from this paper is 
in the modeling methodogy and the tools developed through this research. Section II describes the thermal modeling approach, Section III describes the simulation details, Section IV discusses the results, Section V discusses some challenges for smart node integration and limitations of the current modeling approach, and Section VI provides some concluding remarks.

\section{Thermal Modeling}

The thermal model being developed in this study is for a commercial turbofan engine in the $40,0001 b_{\mathrm{f}}$ thrust class. This decision was made based on the availability and wide acceptance of the existing C-MAPSS40k simulation. Although this is a realistic and well documented engine system simulation, it lacks any physical definition of its geometry. The layout and dimensions of the engine were assumed based on schematics of engines in the same thrust-class in order to provide a tangible basis for the study ${ }^{17}$. It is common in such engines for the bypass flow to be aerodynamically shielded from the core casing. The bypass duct wall creates an interior cavity between itself and the casing. Several slots may exist on the inner bypass duct wall to provide flow paths into the cavity in order to cool the casing and any casing mounted sensors or actuators. Figure 1 provides an example of the described geometry.
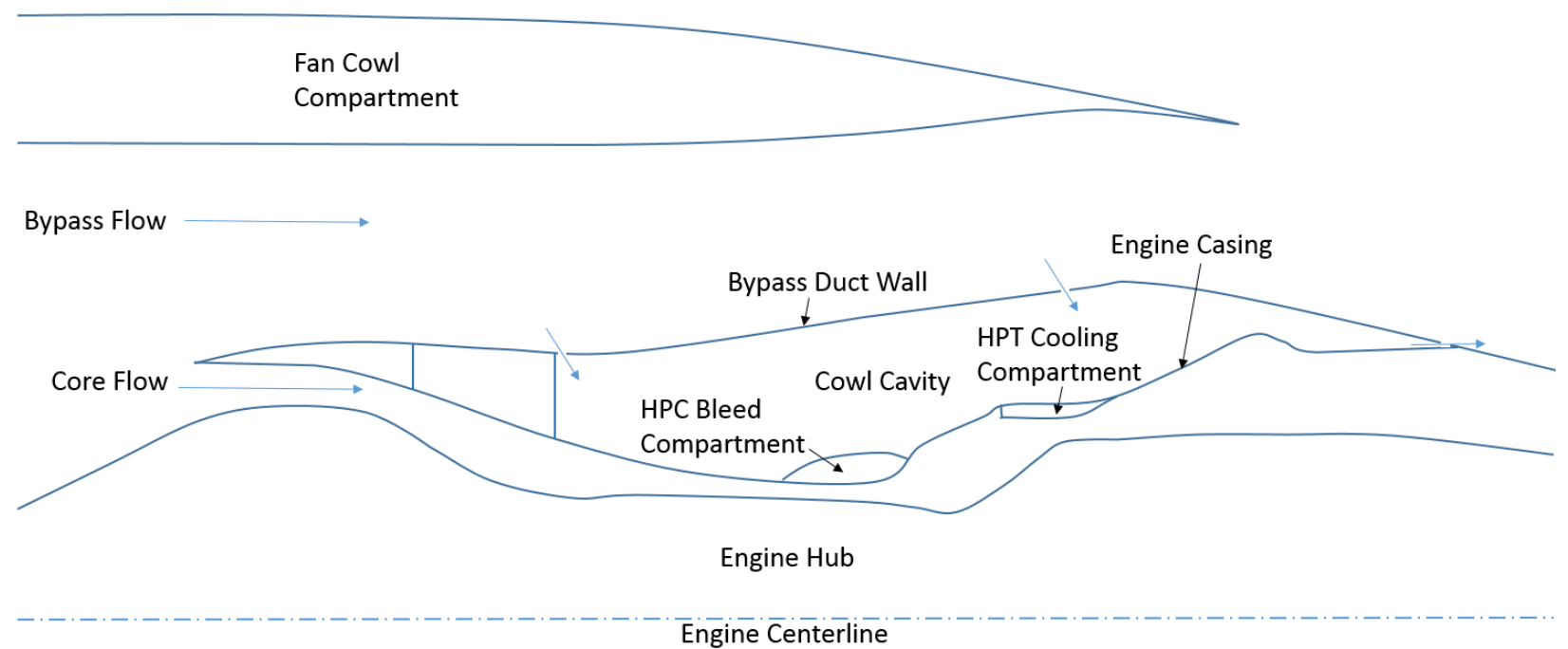

Figure 1. Cross-section of a turbofan engine depicting interior cavity between the engine casing and bypass duct wall

The engine casing geometry is very complex and it is made of several different materials. With air being bled off the bypass duct to cool the cavity, the temperatures in the region surrounding the engine casing could vary due to the influence of cooling bleeds and the mixing of the air within this cavity. Additionally the engine casing temperature in the hot section of the engine is expected to be high enough that the effects of radiation are not negligible. Due to the relatively low flow rate inside the cavity, it is possible that the air within the cavity could extract a significant amount of heat from its hot surroundings, increasing its temperature and changing its flow properties. Circumfential variations could exist due to the presence of various structures inside and outside of the gas paths. Direct experimental data or a 3-D finite element/difference method would be useful but it is beyond the scope of this research at this time. Therefore, it was desired to create a simpler model to estimate the engine casing temperature.

Approximations of the engine casing temperature were made using a 2-D finite difference approach. The approach makes use of a modified version of the Alternating-Direction-Implicit (ADI) technique for integration as is described in Ref. 18. In this approach, the relevant engine structure is discretized axially and radially. First a 1-D finite difference approach is applied to model heat transfer in the radial direction for one half of the time-step and then a 1-D finite difference approach is applied to model the heat transfer in the axial direction for the second half of the time-step. The boundary conditions are set by the neighboring fluids, contacting structures, and radiating surfaces relevant to each component. In the instance of fluids, empirical correlations are used to estimate the convective heat transfer.

Figure 2 provides a schematic of the assumed engine configuration and major components. The modeled structural components are: the engine casing (including the nozzle wall), the inner bypass duct wall, a wall enclosing the bleed cavities around the high pressure compressor (HPC) which will be referred to as the HPC bleed enclosure 
wall, a wall enclosing the cooling cavities around the high pressure turbine (HPT) which will be referred to as the HPT cooling enclosure wall, and a total of 9 vertical walls used for support and or the division of different bleed/cooling flow paths. Several cavities are created by the engine structure which may contain stagnant air or bleed air. Cavities 1, 2, and 3 are between the engine casing and bypass duct wall. HPC cavities 1, 2, 3, and 4 are between the engine casing and the HPC bleed enclosure wall. HPT cavities 1,2, and 3 are between the engine casing and the HPT cooling enclosure wall. On top of the HPT cooling enclosure wall is series of cooling tubes that essentially covers the entire surface. Rather than model these as separate streams of cooling air they are lumped together into HPT cavity 4. Cavity 2 and 3 are supplied with bleed air from the bypass duct. The air in cavity 2 is distributed to the 14 tip clearance cooling tubes and HPT cavity 4 . Air is bled off of the HPC into HPC cavity 1 for the customer bleed and auxiliary purposes such as de-icing. A second bleed exists in the HPC which supplies HPC cavity 2. This air is routed to HPT cavities 2 and 3 to cool the engine casing around the turbine. HPT cavity 1 is supplied with bleed air from the HPC exit. Cavity 1 and HPC cavities 3 and 4 are occupied with dead (i.e. no forced circulation) air.

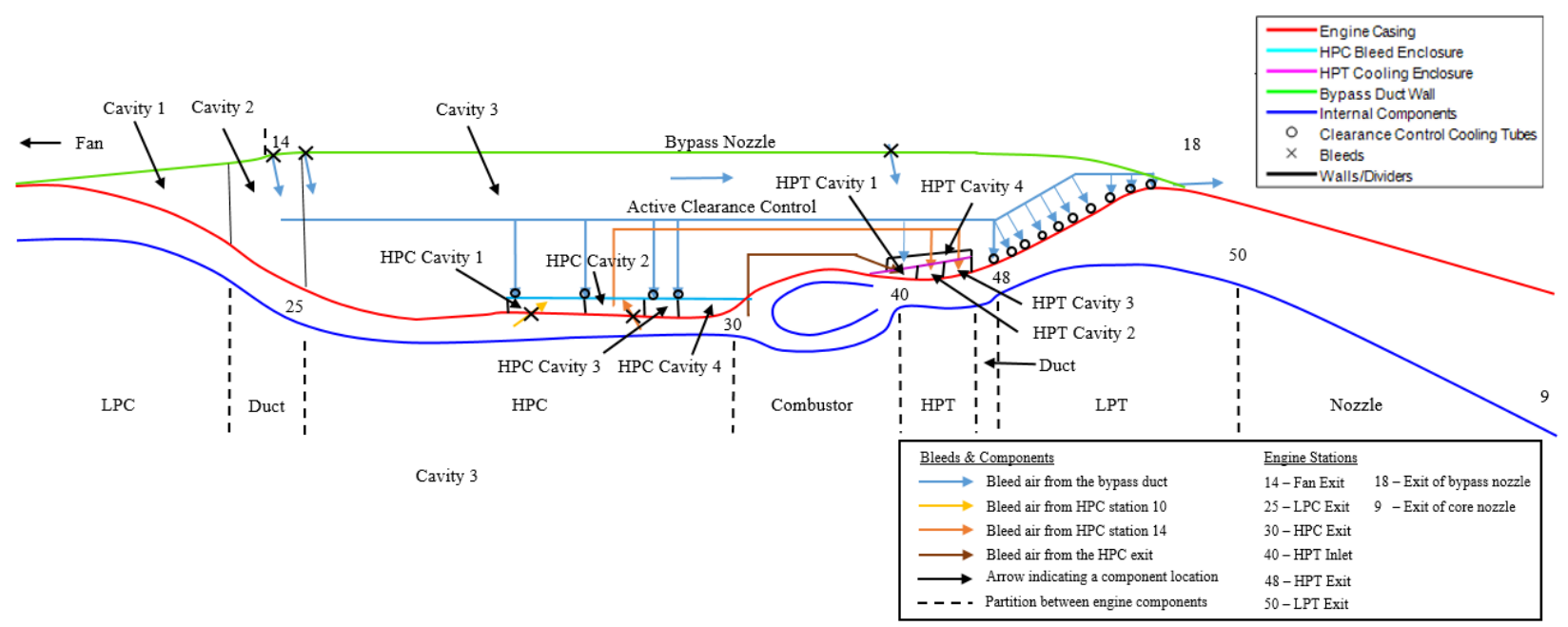

Figure 2. Schematic of the relevant engine components

In Fig. 2 the acronyms LPC and LPT stand for the low pressure compressor and low pressure turbine respectively.

\section{A. Structure Thermal Model}

The structure of the engine is modeled in a modular manner. Each component listed previously is modeled separately and coupled to the rest of the model through its boundary conditions. Each of the structural components are modeled in a similar manner which is based around finding a solution to the partial differential equation given below ${ }^{18}$.

$$
\frac{\partial T}{\partial t}=\frac{1}{\rho C_{p}}\left[\left(\frac{\partial k}{\partial x}+\frac{a k}{x}\right) \frac{\partial T}{\partial x}+k \frac{\partial^{2} T}{\partial x^{2}}\right]
$$

where $k$ is the thermal conductivity of the engine casing material, $\rho$ is its density, $C_{p}$ is its specific heat, $a$ identifies the shape of the geometry ( $a=0$ - planar, $a=1$ - cylindrical disc), $T$ is the temperature, $t$ is the time, and $x$ is the spatial position within the structural element. Note that the material properties can be time-varying in this formulation allowing for temperature dependent material properties and transitions in material to be applicable. Also note that Eq. (1) is a 1-D version of the thermal conduction heat transfer equation which can be used in both the $x$ (or radial) direction and $y$ (or axial) direction to solve a 2-D heat transfer problem using the Alternating Direction Implicit scheme.

The system is discretized and a solution is obtained through the time-marching scheme known as the CrankNicolson method ${ }^{19}$. The time derivative is approximated with a first order forward difference method. The spatial derivatives are modeled with a modified central difference method where the values of the temperatures at the 
current, previous, and next node are each averaged using the current value and the value at the next time-step. The discrete equation for a single interior node of a spatial domain that is generally non-uniform is given by Eq. (2).

$$
\begin{aligned}
& T_{j}^{m+1 / 2}-T_{j}^{m}=\frac{\Delta t}{\rho_{j} C_{p, j}}\left(\frac{\left(k_{j+1}-k_{j-1}\right)}{\left(\delta_{1}+\delta_{2}\right)}+\frac{a k_{j}}{x_{j}}\right) \frac{\left[\frac{1}{2}\left(T_{j+1}^{m}+T_{j+1}^{m+1 / 2}\right)-\frac{1}{2}\left(T_{j-1}^{m}+T_{j-1}^{m+1 / 2}\right)\right]}{\left(\delta_{1}+\delta_{2}\right)} \\
& +\frac{2 k_{j} \Delta t}{\rho_{j} C_{p, j}\left(\delta_{1}^{2}+\frac{\delta_{1}^{3}}{\delta_{2}}\right)}\left[\left(1+\frac{\frac{\delta_{1}^{3}}{\delta_{2}^{2}}-\delta_{1}}{\delta_{2}+\delta_{1}}\right) \frac{1}{2}\left(T_{j+1}^{m}+T_{j+1}^{m+1 / 2}\right)-\left(1+\frac{\delta_{1}^{3}}{\delta_{2}^{3}}\right) \frac{1}{2}\left(T_{j}^{m}+T_{j}^{m+1 / 2}\right)+\left(\frac{\delta_{1}^{3}}{\delta_{2}^{3}}-\frac{\frac{\delta_{1}^{3}}{\delta_{2}^{2}}-\delta_{1}}{\delta_{2}+\delta_{1}}\right) \frac{1}{2}\left(T_{j-1}^{m}+T_{j-1}^{m+1 / 2}\right)\right]
\end{aligned}
$$

where

$$
\delta_{1}=x_{j}-x_{j-1}, \quad \delta_{2}=x_{j+1}-x_{j}
$$

Eq. (2) evaluates the temperature of the node at the end of the first half of the time step. A similar formulation can be derived for the second half of the time step. Note that $\Delta t$ is the time-step, $\Delta x$ is the node thickness, $j$ is the index of the node, and $m$ is the index of the time-step. Here $m$ refers to the previous value where $m+1 / 2$ refers to the new value at the one half time-step mark. Recalling that this equation is applied in each direction for half of the time-step and so the equations are consistent with a time-step of $\Delta t / 2$. The variable $\delta$ is the distance between adjacent nodes. This formulation makes use of generic central difference equations to approximate the first and second derivatives. Those expressions and their derivations can be found in Appendix A. Eq. 2 is first order accurate in time and first order accurate in space. If a uniform discretization is used with Eq. (2) then it becomes second order accurate in space.

There are two types of conduction heat transfer elements in the model. The first is a 2-D heat transfer element that aims to estimate the temperature at every discretized node location. This type of model is used for 9 vertical walls in the structure which are modeled as cylindrical discs with an inner and outer radius. The second type will be referred to in this paper as a pseudo 2-D element in which the structure has been discretized as a 2-D element but variations in temperature are only significant in 1 direction and so the objective is to only estimate the temperature of the structure at the locations in that direction. Applications of this type of conduction heat transfer element are the engine casing, bypass duct wall, HPC bleed enclosure, and HPT cooling enclosure which are relatively thin walls whose temperatures in the radial direction are essentially constant. This allows the axial heat transfer model to lump all of the radial nodes at a given axial location into a single axial node with its temperature being the average. Then the axial heat transfer model is executed using these temperatures. This concept is illustrated with Fig. 3.

Radial Heat Transfer Nodes

\begin{tabular}{|c|}
\hline $\mathrm{T}_{0}$ \\
\hline $\mathrm{T}_{1}$ \\
\hline$:$ \\
\hline$:$ \\
\hline $\mathrm{T}_{\mathrm{j}}$ \\
\hline$:$ \\
\hline$:$ \\
\hline $\mathrm{T}_{\mathrm{N}}$ \\
\hline $\mathrm{T}_{\mathrm{N}+1}$ \\
\hline
\end{tabular}

Axial Heat Transfer Element

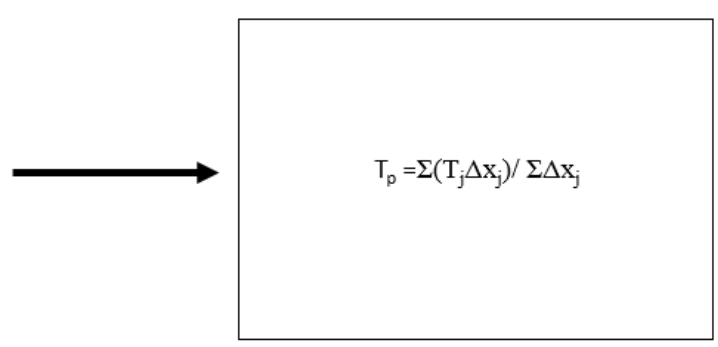

Figure 3. Axial heat transfer node simplification for a single element

Before moving on to the next iteration, the solution is discretized for the next iteration of the radial heat transfer model. The variation of temperatures in the radial direction is retained by applying a shift to the previous radial heat transfer solution at $\Delta t / 2$ that is equivalent to the change in temperature of the axial element in the second half of the time step. In the equation below, the subscript $j$ refers to indices in the radial direction and $p$ refers to indices in the axial direction. 


$$
T_{j}^{m+1}=T_{j}^{m+1 / 2}+\left(T_{p}^{m+1}-T_{p}^{m+1 / 2}\right)
$$

The modeling techniques discussed thus far in this section have been tested and verified with applications to simple problems.

\section{B. Boundary Conditions}

The boundary conditions are set through the surface nodes, which may experience conduction from its neighboring node, convection from the fluid on its outer surface, and radiation from external surfaces. To make the node spacing convenient and to get better resolution of the temperature at the surface, the surface nodes are made to be one half of the thickness of its neighboring interior node ${ }^{19}$. Note that $N$ is the number of interior nodes in the wall.

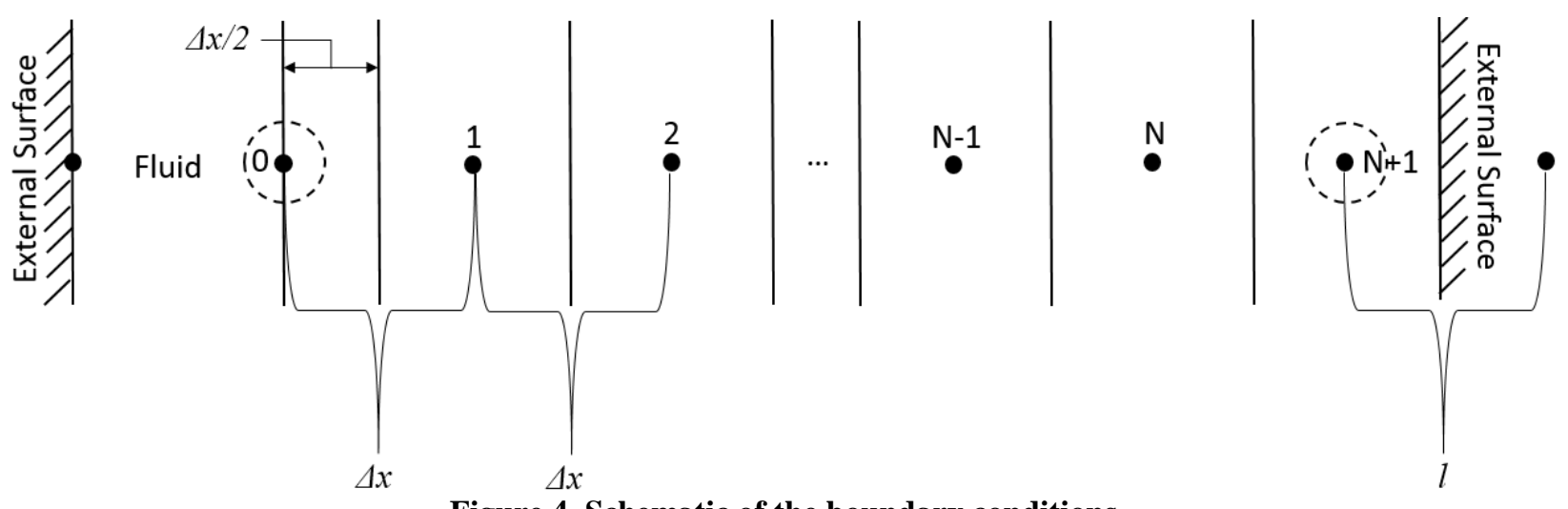

Figure 4. Schematic of the boundary conditions

The surface node temperature is governed by Eq. (4) where the parameters are consistent with the material of the wall, the fluid that is adjacent to it, and radiation from a neighboring structure.

$$
\rho C_{p} \frac{\Delta x}{2} \frac{\partial T}{\partial t}=\frac{k}{\Delta x}\left(T_{\text {inside }}-T_{\text {surf }}\right)+q_{\text {conv }}+q_{\text {rad }}+q_{\text {cond }}
$$

The symbol $q$ is a heat flux while the subscripts conv, rad and cond refer to convection, radiation, and conduction. The subscripts surf and inside refer to the surface node and neighboring interior node respectively. The convective heat flux term and radiation heat flux term will be different depending on the given surface and simulation scenario.

During the in-flight simulations, the convective heat transfer in most locations of the engine are dominated by forced convection from the bypass flow, core flow, and bleeds. Therefore, the convective heat flux can be modeled using the equation:

$$
q_{\text {conv }, \text { flow }}=h_{\text {flow }}\left(T_{\infty}-T_{\text {surf }}\right)
$$

$T_{\infty}$ refers to the temperature of the fluid flowing outside the surface. The convective heat transfer coefficient $h_{\text {flow }}$ for the flow inside the gas paths and cavities are determined using the Dittus-Boelter equation ${ }^{18}$ or Gnielinski's correlation $^{18}$ to approximate the Nusselt number, $\mathrm{Nu}$, based on estimates of mass flow rates and flow areas. The flow areas of the various gas paths and passages were inferred based on the assumed geometry of the engine. The mass flow rates of core and bypass flows were supplied by the engine simulation and the mass flow rates of secondary flow passages were assumed to be a fraction of the flow rate in the main gas path that supplies it. The calculation of $h_{\text {flow }}$ requires the specific heat $C_{p}$, dynamic viscosity $\mu$, and thermal conductivity $k$ of the surrounding air be known. These quantities were approximated using the empirical equations of Ref. 20 and 21 . The mass flow rates of the core and bypass flows are large and fast moving. This leads to the assumption that heat addition into these flows from the surfaces that they come in contact with is negligible compared to the energy of the fluid characterized by the product of its enthalpy and mass flow rate. This is a good assumption for many of the flow passages around the engine. However, cavity 3 has a relatively small mass flow rate and therefore the heat transfer could significantly influence the enthalpy of the air in the cavity. The temperature of the air in the cavity is determined at each discrete location using an energy balance. 


$$
\left(\dot{m}_{\text {cavity }, p-1}+\dot{m}_{\text {bleed }}\right) C_{p, p} T_{\text {cavity }, p}=\dot{m}_{\text {cavity }, p-1} C_{p, p-1} T_{\text {cavity }, p-1}+\dot{m}_{\text {bleed }} C_{p, \text { bleed }} T_{\text {bleed }}+Q
$$

The subscript $p$ is the index of current axial cavity element. The subscript bleed refers to a bleed flow entering the cavity at the current axial location. $Q$ is the heat transfer into the fluid in the cavity by the walls of the engine casing and bypass duct.

$$
Q=h_{\text {flow }} A_{\text {case }, p}\left(T_{\text {case }, p}-T_{\text {cavity }, p}\right)+h_{\text {flow }} A_{\text {duct }, p}\left(T_{\text {duct }, p}-T_{\text {cavity }, p}\right)
$$

where

$$
A_{\text {case }, p}=2 \pi R_{\text {case }, p} \Delta y, \quad A_{\text {duct }, p}=2 \pi R_{\text {duct }, p} \Delta y
$$

Eq. (6) can be re-arranged to provide a general expression for the temperature of the fluid in the cavity at a particular location.

$$
T_{\text {cavity }, p}=\frac{\dot{m}_{\text {cavity }, p-1} C_{p} T_{\text {cavity }, p-1}+\dot{m}_{\text {bleed }} C_{p, b l e e d} T_{\text {bleed }}+h_{\text {flow }} A_{\text {case }, p} T_{\text {case }, p}+h_{\text {flow }} A_{\text {duct }, p} T_{\text {duct }, p}}{\left(\dot{m}_{\text {cavity }, p-1}+\dot{m}_{\text {bleed }}\right) C_{p}+h_{\text {flow }}\left(A_{\text {case }, p}+A_{\text {duct }, p}\right)}
$$

The convective heat transfer coefficient was determined using Gnielinski's correlation.

During the heat soak back simulation scenario there is no air flowing through the engine and as a result free convection becomes a dominant heat transfer mechanism. Free convection is also a dominant form of heat transfer on the interior surfaces of the structure surrounding cavity 1, and HPC cavity 3 and 4 during the in-flight simulation scenario due to there being no bleed flows in these cavities. These cases are modeled using one of the following terms.

$$
\begin{gathered}
q_{\text {conv }, \text { free }}=h_{\text {free }}\left(T_{\infty}-T_{\text {surf }}\right) \\
q_{\text {conv }, \text { free }}=\frac{1}{R_{\text {surf }}} \frac{k_{\text {eff }}\left(T_{\text {surf }, \text { ext }}-T_{\text {surf }}\right)}{\ln \left(R_{o} / R_{i}\right)}
\end{gathered}
$$

In Eq. (9) $h_{\text {free }}$ is the free convection heat transfer coefficient and it is estimated using an empirical correlation recommended by Churchill and Chu in Ref. 22 for isothermal cylinders. Eq. (10) applies to concentric cylinder geometries and was proposed in Ref. 23. The variable $k_{\text {eff }}$ is the effective thermal conductivity of the convecting air within the cavity, $R$ is a radius, and the subscripts surf, surf,ext, $o$, and $i$ refer to the current surface, exterior surface, outer surface, and inner surface respectively. The calculation of $h_{\text {free }}$ and $k_{\text {eff }}$ requires the specific heat $C_{p}$, dynamic viscosity $\mu$, and thermal conductivity $k$ of the surrounding air be known and so Ref. 20 and 21 were used to estimate these quantities.

Several of the surfaces are expected to experience what could be significant impacts from radiation, especially in the hot section of the engine near the burner and turbines. The outside of the bypass duct wall is not expected to get hot enough for radiation to significantly impact the temperature of its surface and so radiation is neglected. In the cases where radiation is considered, the heat flux from the distant radiating surface to the surface of interest is estimated by the following equation ${ }^{18}$.

$$
q_{\text {rad }}=u\left(T_{\text {surf }, \text { rad }}-T_{\text {surf }}\right)
$$

The variable $u$ is the radiation heat transfer coefficient defined as: 


$$
u=\frac{\sigma}{\frac{1}{\varepsilon_{\text {surf }, \text { ext }}}+\frac{1-\varepsilon_{\text {surf }}}{\varepsilon_{\text {surf }}}\left(\frac{R_{\text {surf }, \text { ext }}}{R_{\text {surf }}}\right)}\left(T_{\text {surf }, \text { ext }}^{2}+T_{\text {surf }}^{2}\right)\left(T_{\text {surf }, \text { ext }}+T_{\text {surf }}\right)
$$

Here $\varepsilon$ is the surface emissivity, and $\sigma$ is the Stefan-Boltzmann constant. The inner surface of the engine casing is exposed to radiation from the internal engine components but creating a complex thermal model of the internal engine components is beyond the scope of this study. For the purposes of this study the internal engine components were approximated using a lumped mass model to get the temperature at each discrete point.

Several of the structural components come in contact with one another in one or more places. This requires a conduction boundary condition which is simply stated below:

$$
q_{\text {cond }}=\frac{k}{l}\left(T_{\text {cond }}-T_{\text {surf }}\right)
$$

where $T_{\text {cond }}$ is the temperature of the neighboring node in the adjoining structural component and $l$ is the distance between the two nodes. In the case of a conduction boundary condition the "surface" node was embedded in the structure.

Eq. (4) can be discretized using a similar method as for the interior nodes. The general expression is given below

$$
T_{\text {surf }}^{m+1 / 2}-T_{\text {surf }}^{m}=\frac{\Delta t}{2 \rho C_{p} \Delta x}\left\{\begin{array}{l}
\frac{k}{\Delta x}\left[\left(T_{\text {inside }}^{m+1 / 2}+T_{\text {inside }}^{m}\right)-\left(T_{\text {surf }}^{m+1 / 2}+T_{\text {surf }}^{m}\right)\right]+\left(q_{\text {conv }, d}+q_{\text {rad }, d}\right) \\
+\frac{k}{l}\left[\left(T_{\text {cond }}^{m+1 / 2}+T_{\text {cond }}^{m}\right)-\left(T_{\text {surf }}^{m+1 / 2}+T_{\text {surf }}^{m}\right)\right]
\end{array}\right\}
$$

where $q_{c o n v, d}$ and $q_{r a d, d}$ are discretized versions of $q_{c o n v}$ and $q_{r a d .}$

\section{Solution}

Eq. (2) and (13) can be rearranged to place all of the new temperature terms on the left hand side of the equations and all other terms on the right hand side to produce a linear system of equations where the expression on the right hand side is made entirely of known quantities. Note that in order to obtain a linear system, the heat transfer coefficients relevant to the boundary conditions are evaluated using the current properties of the structure and fluid. If this is done for each node, the system can be written in the form of a linear tridiagonal system that can be efficiently solved using Thomas's algorithm ${ }^{19}$.

\section{Special Considerations for Heat Soak Back}

Reference 24 is one of very few documents in the literature that attempt to model the heat soak back problem. It provides some background on the difficulties of modeling the heat soak back phenomena. Here a simplified approach was taken. The heat soak back portion of the simulation has two parts: a spool-down segment, and a heat soak segment. During the spool-down segment the engine shafts continue to spin for some time after shutdown before they completely stop. In this time, cool air is being pulled through the engine while warm air is being pushed out. This leads to a significant decrease in the gas path temperatures at the beginning of the heat soak back portion of the simulation. This portion of the dynamics was modeled by forcing the fuel flow demand in the C-MAPSS40k engine model to zero at the end of the in-flight simulation. The results of the simulation were used until the operating point moved off the compressor and or turbine maps of the engine model. At that point the remaining dynamics of the spool-down process were modeled as first order transfer functions. The mass flow rates and pressures were assumed to approach 0 and the ambient pressure respectively. The temperature of the air in the bypass duct was assumed to approach the ambient temperature, and the final temperatures inside the core gas path were initialized with a guess and iterated on until a smooth transition was observed between the spool-down simulation segment and the heat soak simulation segment.

During the heat soak segment of the simulation, the temperature of the air in the bypass duct was assumed to remain at the ambient temperature. Given that this is a high bypass engine with plenty of air to occupy the bypass flow path this seemed like a reasonable assumption. The temperature of the air in the core gas path was obtained by 
modeling the core gas path as a pseudo 2-D conduction member initialized with the temperatures in the gas path at the end of the spool-down simulation segment. The boundary conditions were set by the internal engine components and engine casing on the bottom and top respectively, and the air temperature at the inlet of the LPC and exit of the nozzle were assumed to be the ambient temperature. The conductivity of the air in the core and the convective heat transfer coefficients in the core and bypass ducts where tuned such that the thermal time constant of the heat soak back simulation resembled the expected cool-down time of the engine.

\section{Simulation Description}

C-MAPSS40k provides the needed temperatures, pressures, and mass flow rates. All of the temperatures and pressures provided by C-MAPSS40k are total values with the exception of the exit nozzle temperatures and so the model should be conservative in this regard since the total temperature should be greater than or equal to the temperature of the air that comes in contact with the structure. Because C-MAPSS40k is a 0-D simulation, it does not provide spatial fidelity in the temperature profile throughout the engine. These values are only available at a few engine stations. Therefore, the temperature at each axial location was interpolated based on the current temperatures at the recorded stations. Figure 5 shows an example plot of the core and bypass temperature profile along the length of the engine at a given instant in time.

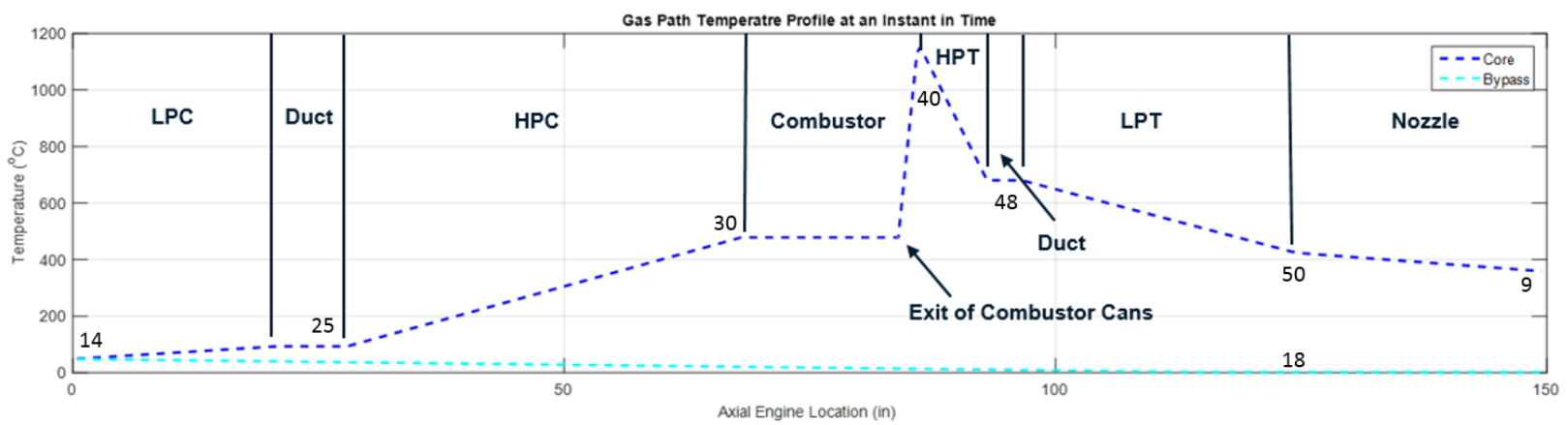

Figure 5. Example of the gas path temperatures along the length of the engine with station numbers

A simplified engine geometry was created for this study similar to the one depicted in Fig. 2. The geometry was loosely based on dimensions gleaned from public sources for turbofan engines in the $40,000 \mathrm{lb}$ thrust class ${ }^{17}$. The materials and thicknesses of the engine walls were set based on limited information supplied in Numerical Propulsion System Simulation (NPSS) Weight Analysis of Turbine Engines (WATE) files ${ }^{17}$ for engines in the $40,0001 b_{\mathrm{f}}$ thrust class. The assumed materials are provided in Table 1 .

Table 1. Materials of relevant engine components

\begin{tabular}{|l|l|}
\hline ENGINE COMPONENT & MATERIAL \\
\hline CASING (LPC) & Titanium-6Al-4v \\
\hline CASING (HPC) & Udimet 500 \\
\hline CASING (BURNER) & TD Nickel \\
\hline CASING (HPT) & TD Nickel \\
\hline CASING (LPT) & V-57 \\
\hline CASING (NOZZLE) & Steel 4340 \\
\hline COMPONENT (LPC) & Titanium-6Al-4v \\
\hline COMPONENT (HPC) & Titanium-6Al-4v \\
\hline COMPONENT (COMBUSTOR) & TD Nickel \\
\hline COMPONENT (HPT) & Inconel 718 \\
\hline COMPONENT (LPT) & Inconel 718 \\
\hline BYPASS DUCT WALL & Aluminum 2024 \\
\hline
\end{tabular}

Note that different materials and geometries may be more relevant to modern and future gas turbine engines, particularly as it concerns the bypass duct wall. These differences could result in a different thermal environment than what is predicted in this study, especially for the bypass duct wall and inside the cowl cavity. 
The flight profile supplied to C-MAPSS40k was derived from actual flight data available from Ref. 16. This simulation should be representative of a typical flight for a commercial aircraft. It begins with a take-off, several small maneuvers during ascent, a cruise portion, several small maneuvers during descent, and it ends with a landing. There is also data recorded for the engine before take-off and after landing which should help to characterize the engine casing temperature on the runway and for the issue of heat soak back. Figure 6 and 7 show the flight profile. In Fig. 6 dTamb is the difference of the actual and standard atmospheric temperature. The final plot in Fig. 6 is the Power Lever Angle (PLA). It is the command provided by the pilot to demand more or less power/thrust from the engine. On this scale $40^{\circ}$ is idle and $80.5^{\circ}$ is full power. For the in-flight simulation shown below, it is assumed that the engine has just been started and all structural components are initialized with a uniform temperature equal to the ambient air temperature.
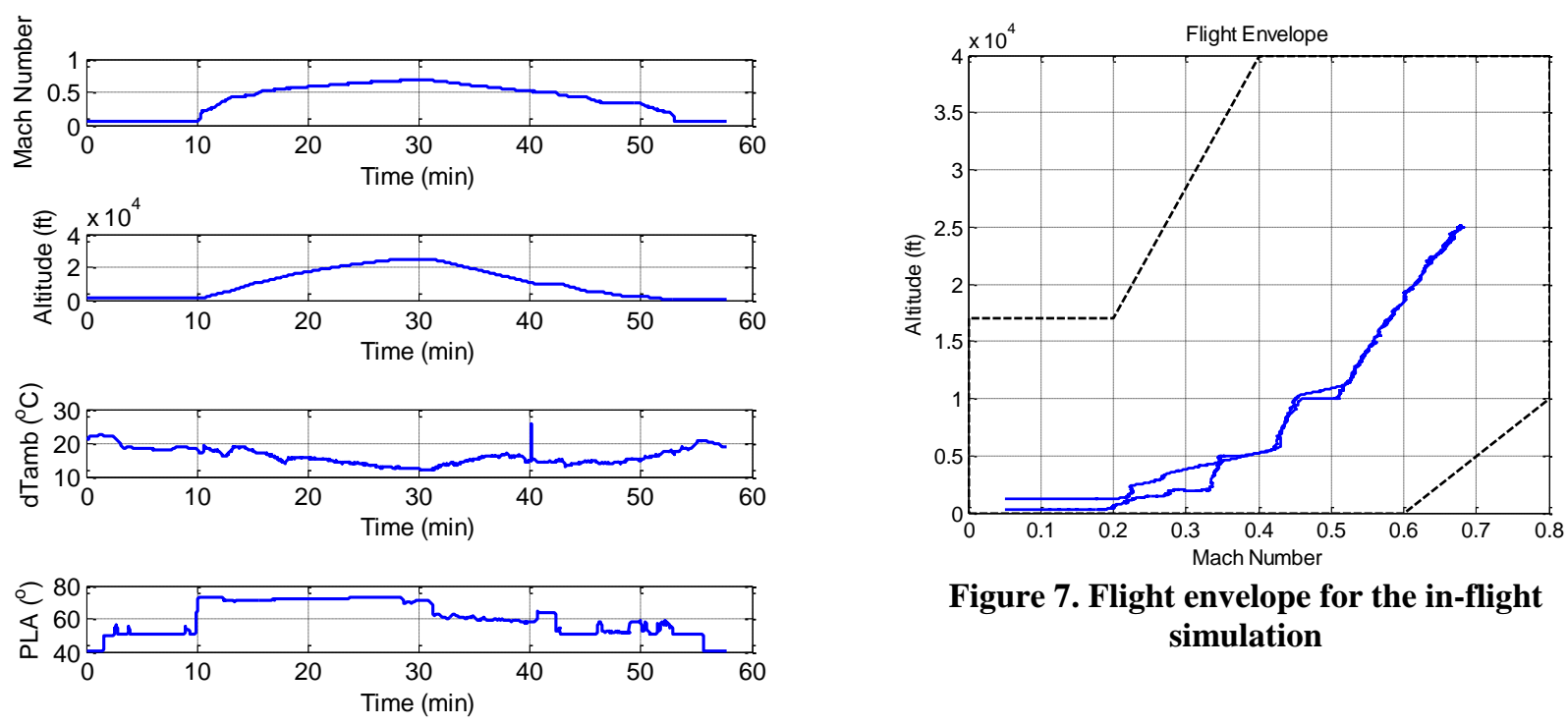

Figure 7. Flight envelope for the in-flight simulation

\section{Figure 6. Flight data input profile for the in-flight simulation}

After the in-flight simulation of the engine's thermal response was complete, a spool-down simulation segment was executed followed by the heat soak segment of the simulation. The spool-down simulation and beginning of the heat soak segment were iterated until the final core gas path temperatures transitioned smoothly into the heat soak simulation. Each simulation was initialized using the results from the final time-step of the previous simulation segment.

\section{Results}

The results in this section were produced for a fictional engine with a simplified geometry and several assumptions have been made about its operation. The simulation scenario is not inclusive of every nominal and offnominal condition through which an engine may have to operate. Furthermore, there is no data to validate results nor provide a general idea as to what the environment is really like. Therefore, the purpose of the results is to illustrate the use of the thermal analysis methodology which could be applied to other engines and more generally in different engineering problems. It also attempts to provide a rough idea of what the thermal environment around a commercial gas turbine engine might be as it pertains to placement of electronics for DEC applications.

The simulation scenario described in the previous section was executed and evaluated. Figure 8 shows the maximum and minimum temperature and rate of change in temperature $d T / d t$. On the x-axis of the plots is the axial location inside the engine where 0in corresponds to the front of the LPC. The y-axis is the temperature or rate of change of the temperature as indicated. The top left plot shows the maximum temperature profile. There are 2 dashed horizontal lines on this plot at $225^{\circ} \mathrm{C}$ and $500^{\circ} \mathrm{C}$ to provide a prospective of the structures temperature relative to conservative estimates of the capabilities of SOI and SiC electronics. The top right shows the minimum temperature profile, the bottom left shows the maximum rate of change in the temperature, and the bottom right plot 
shows the minimum rate of change in temperature. The results encompass the in-flight, spool-down, and heat soak segments of the simulation.

A maximum temperature of $\sim 1200^{\circ} \mathrm{C}$ was reached by the engine casing at the inlet of the HPT. Due to the presence of the HPT bleed enclosure this is not a feasible mounting location for electronics and so the hottest location that has the potential for mounting electronics is on the engine casing near the front of the LPT with temperatures approaching $800^{\circ} \mathrm{C}$. This is well above the capabilities of any foreseeable electronics technology. These particular results suggest that $\mathrm{SiC}$ electronics would be restricted to use in the front section of the engine. This is without considering how the design of the enclosure around the electronics or any auxillary cooling schemes may impact the local thermal environment. The possible mounting areas includes the HPC but all locations downstream are too hot or impractical. The presense of the cooling flow around the HPT cooling enclosure could make parts of it a feasible mounting location. However the presence of cooling tubes and potential for large temperature gradients and temperature swings makes this a challenging location to mount electronics. There is potential to mount the $\mathrm{SiC}$ electronics on the bypass duct wall at any axial location but there are many challenges to this which will be discussed later. For SOI electronics the constraints are more stringent, limiting the mounting locations to be on the engine casing forward of the front portion of the HPC or on the bypass duct wall. The rate of change in temperature for the structure ranged from $\sim-2.5^{\circ} \mathrm{C} / \mathrm{sec}$ to $\sim 7.2^{\circ} \mathrm{C} / \mathrm{sec}$. The fastest rates tend to occur in locations where temperature gradients and strong convection promote heat transfer.
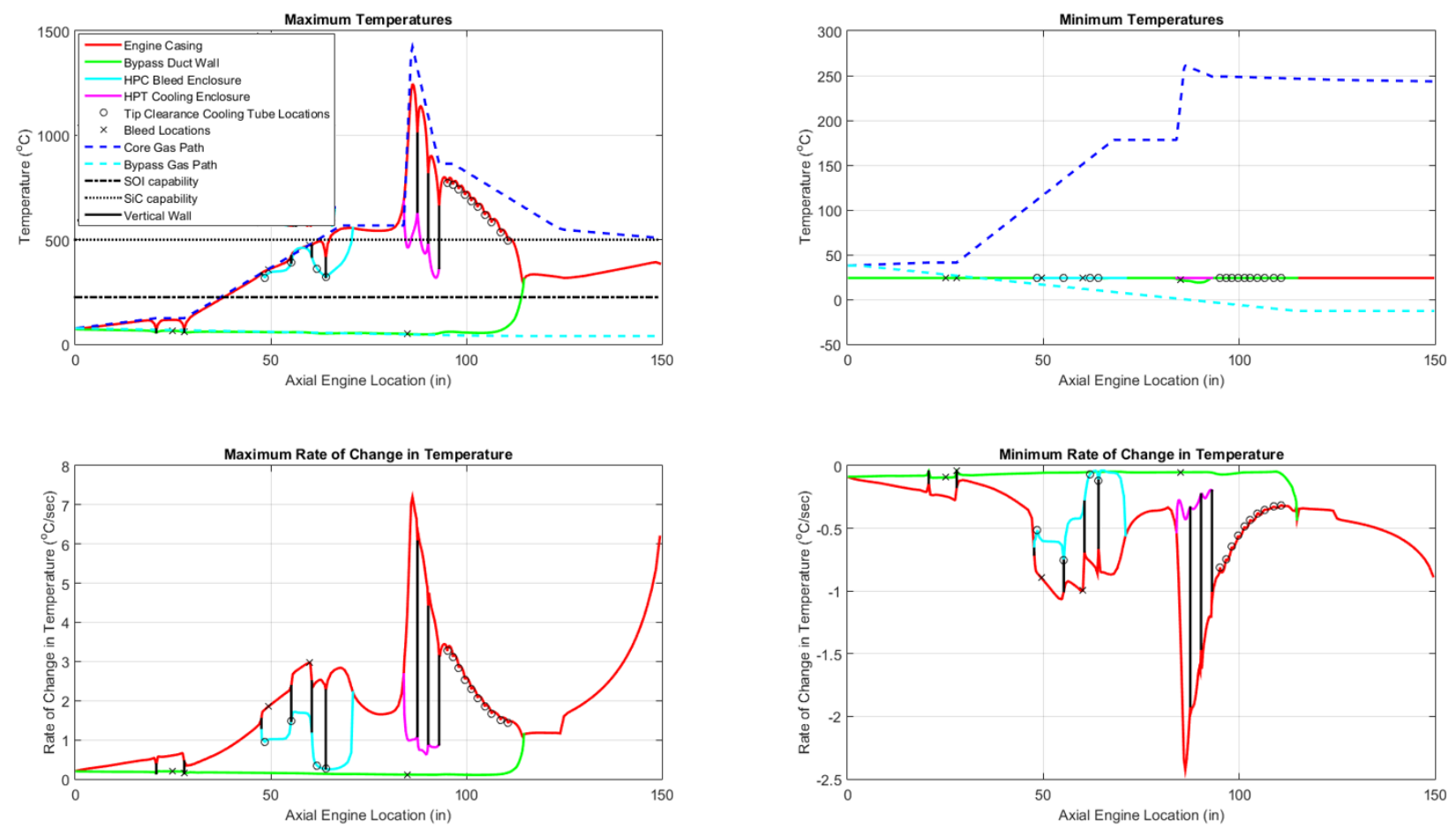

Figure 8. Engine temperature profile and rate of change in temperature

Most of the maximum temperatures were observed to occur during the ascent and cruise portion of the flight taking place between $\sim 10 \mathrm{~min}$ to $32 \mathrm{~min}$ of the flight profile. The time that the actual maximum occurred at a specific location was dependent on the rate of heat transfer which is dependent on the mechanisms of heat transfer and heat quality at the specific location. The temperature vs. time response of a few potential electronic mounting locations is given in Appendix B in Fig. 11 - 16 to provide a better idea of the dynamic response. Temperature margins with respect to the assumed temperature range of reliable operation of present day (PD), silicon-on-insulator (SOI), and silicon-carbide ( $\mathrm{SiC}$ ) electronics are evaluated at several locations in Appendix C. In Fig. 17 the time at temperature information is analyzed, Fig. 18 provides overall average and minimum margin information, and Fig. 19 provides minium margin information for each phase of flight (taxi, take-off/climb, cruise, etc.). These figure suggest several things: (1) dynamic responses within the structures can vary significantly as can be seen with the HPC bleed enclosure; (2) the bypass duct wall has the most favorable temperature environment; (3) worst case temperatures are typically only experienced for a small fraction of the overall flight; and (4) the lowest temperature margins are likely to occur during the take-off/climb portion of the flight. In general the largest rates of temperature change were 
observed after significant and sustained changes in PLA. Quick perturbations in PLA were damped out in the thermal response of the structure due to its slow dynamics. The increasing rates of change in temperature for the structure are generally larger in magnitude than the decreasing rates of change in temperature. This is likely related to several factors including the observation that the gas path dynamics are typically slower when the power level is decreased due to the inertia in the shafts. Another contributing factor could be that a reduction in power level will decrease the mass flow rates through the engine which results in lower convective heat transfer coefficients and thus slower transients.

The temperature of the air inside cavity 3 for which the electronics will likely be mounted was observed to vary throughout the cavity. Generally the temperature inside the cavity increases downstream with the exception of a decrease in temperature at the location of the second bleed into the cavity from the fan duct. Figure 9 shows an example of the temperature profile inside cavity 3 at an instant in time while Fig. 10 shows the maximum and minimum temperatures experienced inside the cavity throughout the flight.

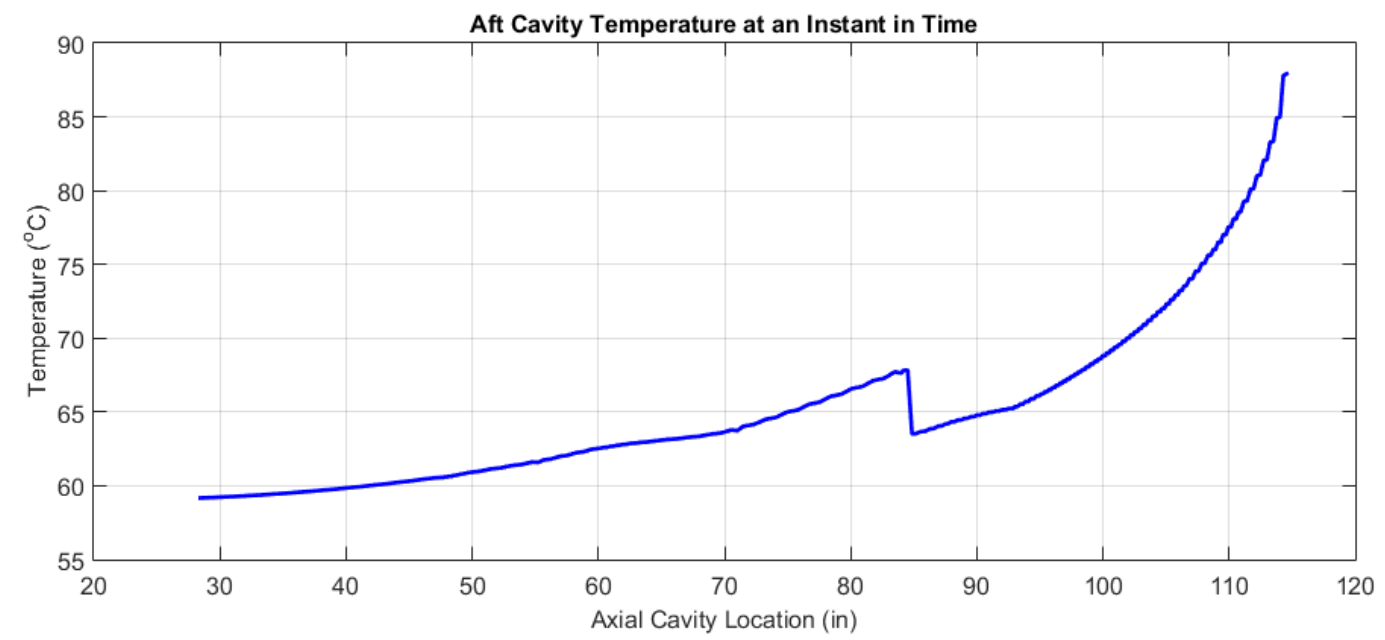

Figure 9. Temperature profile inside cavity 3 at an instant in time
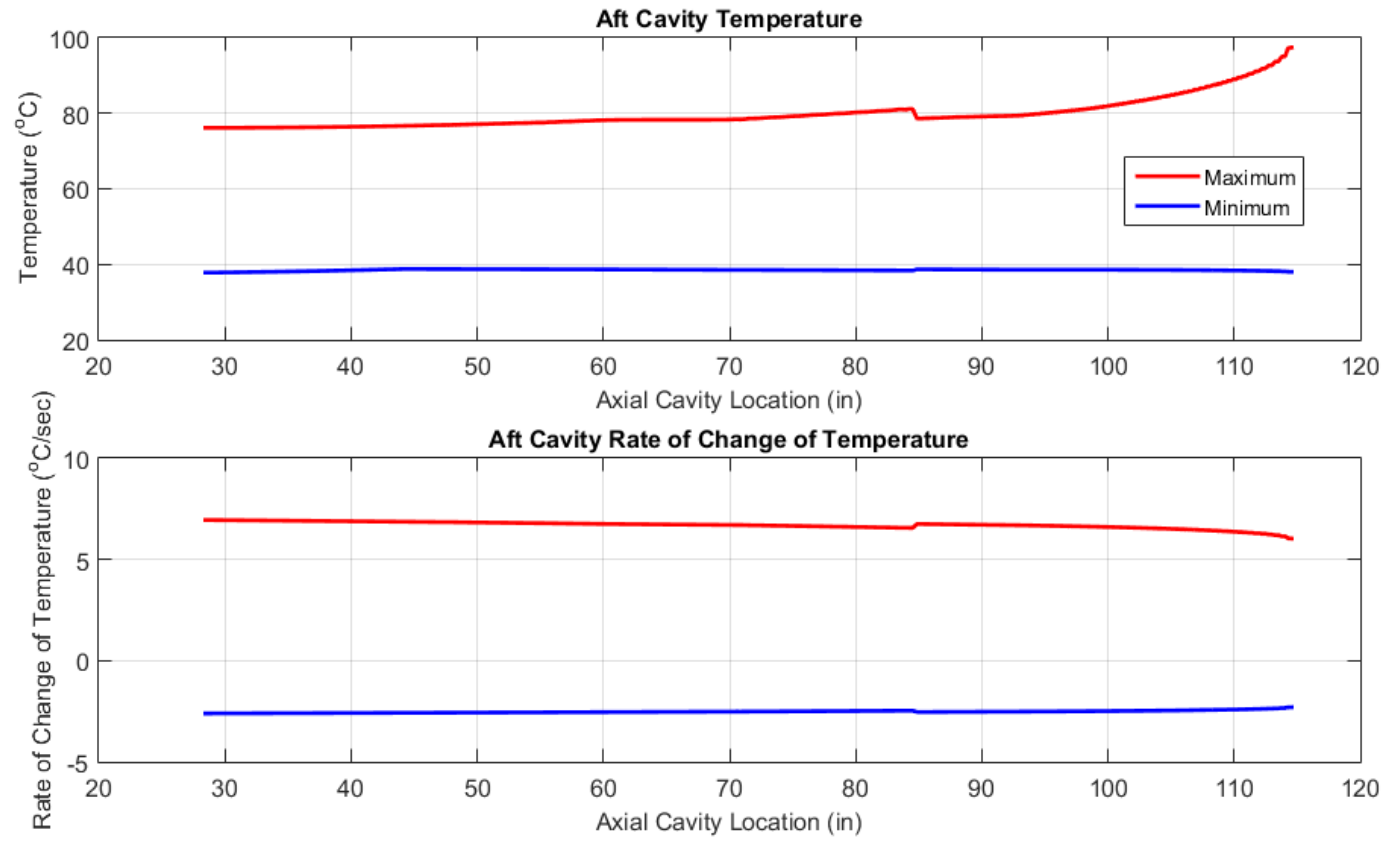

Figure 10. Maximum and minimum temperatures experienced inside cavity 3 
The maximum and minimum temperatures experienced in cavity 3 are $\sim 100^{\circ} \mathrm{C}$ and $\sim 38^{\circ} \mathrm{C}$ respectively. The maximum and minimum rates of change in temperature were observed to be $\sim 7^{\circ} \mathrm{C} / \mathrm{sec}$ and $\sim-2.6^{\circ} \mathrm{C} / \mathrm{sec}$. Note that there is uncertainty about the mass flow rate in cavity 3 as well as the other secondary flow compartments. During the in-flight simulation the mass flow rate inside cavity 3 was between 1 and $4 \mathrm{lb}_{\mathrm{m}} / \mathrm{sec}$ or about 10 and 35 volume changes per minute based on the volume of the cowl cavity (cavity 3 ).

The spool-down and heat soak segments of the simulation did not impart any major constraints. During the heat soak back segment of the simulation, heat was observed to flow radially and axially from the hot parts of the engine to the cooler parts as anticipated. This is attributed mainly to conduction and radiation. This was especially evident in the HPT cooling enclosure wall, which increased in temperature by $\sim 40^{\circ} \mathrm{C}$. The bypass duct wall also increased in temperature near the combustor by $\sim 10^{\circ} \mathrm{C}$, and at the LPT, near the intersection with the engine casing by as much as $\sim 25^{\circ} \mathrm{C}$. The effect of heat soak back could be seen in the bypass duct wall in the vicinity of the walls connecting it to the engine casing near the LPC. After the engine shut down, the temperature in this region remained elevated much longer than its surroundings. Of all of the structure effected by heat soak back, only the bypass duct wall reached temperatures that exceeded the maximum that it experienced during the in-flight simulation. Keep in mind that in this flight scenario the pilot landed, reduced the power level of the engine, and allowed the engine to run for a short time before shutting it down. Had the engine been shut down from a high power setting after allowing the structure to reach a steady-state temperature, these results could be very different. However, based on these results it appears that heat soak back will not have a major impact on electronic constraints assuming that the proper shutdown procedures are followed.

The heat soak back portion of the model was tuned to match the perceived cool-down times of the engine. After the engine shutdown it took $20-30 \mathrm{~min}$ for nearly all of the bypass duct wall to reach a temperature that is cool enough to touch without a severe risk for skin burns. This temperature was taken to be $49^{\circ} \mathrm{C}\left(120^{\circ} \mathrm{F}\right)$ based on the practices of process engineers in regards to safe-to-touch insulation temperature standards. It took roughly $1 \mathrm{hr}$ and $20 \mathrm{~min}$ for nearly all of the engine casing to reach such a temperature. After 2 hours there were still portions of the HPC bleed enclosure and HPT cooling enclosure that slightly exceeded the safe touch temperature but all other structure was below this temperature. These components take longer to cool due to there being more mass and more places to store heat in these parts of the structure.

\section{Discussion}

The bypass duct wall has the most favorable temperature environment but it poses several challenges. For one, this requires that cables be routed from the engine casing where the hardware is mounted to the bypass duct where the smart node is mounted. As a result, the cable would be directly exposed to the flow within the cavity. This inconvenience is further complicated when considering that engine nacelles are often hinged off of the wing/engine pylons to make the engines accessible for servicing. Therefore, opening the engine nacelle would stretch the cables between the smart node and it's hardware. It is clear that smart node placement could be further limited based on accessibility and maintainability needs. Some obvious options include:

- Design in an excessive cable length for the smart nodes such that the engine nacelle can be fully opened without disconnecting the node. This option has obvious weight drawbacks and presents the challenge of securing the extra cabling.

- Place all of the smart nodes above the engine on the engine pylon to minimize the cable length. This could make the smart nodes hard to get to and perform maintanence on. This is also expected to be a less favorable thermal environment considering that heat rises due to buoyancy forces which could mean significantly hotter temperatures, especially following an engine shutdown.

- Place all of the smart nodes below the engine at the bottom of one of the two engine nacelle doors. When maintanence is required, the door without mounted electronics can be opened first. Then the electronics can be disconnected from the hardware on the engine to allow the other nacelle door to open freely.

Another issue associated with placing electronics on the bypass duct wall is that it is typically designed by the airframers or a third party vendor and not the engine manufacturers. Therefore if an engine manufacturer and or their control system contractors are designing the control system and want to place control system components on the bypass duct wall, then a collaborative effort will be needed to assure seamless integration with the airframe as well as proper testing and validation.

It should be kept in mind that the simulation scenario was not a worst case and therefore more stringent constraints may need to be enforced. This study also did not consider how the design of smart nodes, their enclosures, and cooling schemes could impact smart node placement. The presented model is a simplified version of reality with several assumptions and no available data from an actual engine or high fidelity simulation to compare 
the results with for verification. The selection of materials, the assumed and simplified geometries, lack of attention to additional thermal consideration such as thermal coatings that may be present, the assumed simplistic and passive cooling schemes (such as including assumed mass flow rates for secondary flows), and the use of simplistic empirical equations to estimate the convective heat transfer coefficients among other considerations are all contributing factors to uncertainty in the models results. Off-nominal operation of the thermal management system such as opening of doors in the cowl cavity, thrust reversal operation, and emergency conditions such as an engine fire, could have significant implications on the thermal environment. Clearly things are more complicated in reality and without a firm understanding of how these parameters and off-nominal conditions vary and affect the thermal response independently and in combination, it is hard to establish a bound on the uncertainty. Further knowledge about the variation of all relevant contributing factors to the engines thermal environment and their impact on the thermal response of the engine structure would be needed to establish such bounds. This may require an extensive parametric study and or data from an actual engine. Nevertheless the tools developed through this process are generic enough that they should be adaptable for use in future studies where these parameters are better defined and/or engine test/flight data is available for tuning the model. This is a problem that is very much dependent on the geometry and performance of the engine, and the thermal management techniques that the engine employs. One thermal model cannot be used to characterize constraints for all electronics that could be mounted on any specific engine structure, but it may provide an idea of requirements for similar engines. With that said, the developed tools should serve to better understand the thermal environment of gas turbine engines and the constraints it places on its control system. In addition, these tools could aid in the design of smart nodes and their packaging.

\section{Conclusion}

A model has been developed to help characterize the temperature environment of the engine structure relevant to mounting electronics to the engine for the purpose of enabling Distributed Engine Control. The model has been described and applied to a real flight scenario. Both in-flight and heat soak back scenarios have been considered. The results from the simulations appear to reflect the physics of the problem regarding the trends in steady-state temperatures and thermal transient responses. Based on the results, inferences have been made about where smart nodes could be located on the engine structure for this specific application. The most promising areas for mounting electronics appear to be the front portion of the engine casing around the high pressure compressor (HPC), portions of the HPC bleed enclosure with capabilities similar to silicon carbide electronics, and the bypass duct wall. The bypass duct wall has the most favorable temperature environment but it poses several challenges. Those challenges were discussed and some potential ways to address those challenges were proposed. Some additional work may be warranted for addressing modeling uncertainties but this is a good start. Regardless, the techniques and tools used in this study could be useful in the development of new models tailored to a specific problem.

\section{Appendix A: Finite Difference Derivations}

To generalize the discrete differential equations for nodes with neighboring nodes of different thicknesses, new central difference expressions for the first and second derivative are derived using Taylor series expansions. It was necessary to derive an expression for the first derivative. Eq. (14) and (15) are Taylor series approximations of the value of a generic function $f(x)$ at $x-\delta_{1}$ and $x+\delta_{2}$.

$$
\begin{aligned}
& f\left(x-\delta_{1}\right)=f(x)-\delta_{1} f^{\prime}(x)+\frac{1}{2} \delta_{1}^{2} f^{\prime \prime}(x)-\ldots \\
& f\left(x+\delta_{2}\right)=f(x)+\delta_{2} f^{\prime}(x)+\frac{1}{2} \delta_{2}^{2} f^{\prime \prime}(x)+\ldots
\end{aligned}
$$

Eq. (14) was subtracted from Eq. (15) to obtain the following expression for the first derivative of $f(x)$.

$$
f^{\prime}(x)=\frac{f\left(x+\delta_{2}\right)-f\left(x-\delta_{1}\right)}{\delta_{2}+\delta_{1}}+O(\delta)
$$


Note that in the case where the discretization is uniform $\left(\delta_{1}=\delta_{2}\right)$ the order of accuracy is $O\left(\delta^{2}\right)$. Next the second derivative of $f(x)$ was considered. The Taylor series approximations of the value of a generic function $f(x)$ at $x-\delta_{I}$ and $x+\delta_{2}$ are given below.

$$
\begin{aligned}
& f\left(x-\delta_{1}\right)=f(x)-\delta_{1} f^{\prime}(x)+\frac{1}{2} \delta_{1}^{2} f^{\prime \prime}(x)-\frac{1}{6} \delta_{1}^{3} f^{\prime \prime \prime}(x)+\frac{1}{24} \delta_{1}^{4} f^{\prime \prime \prime \prime}(x)-\ldots \\
& f\left(x+\delta_{2}\right)=f(x)+\delta_{2} f^{\prime}(x)+\frac{1}{2} \delta_{2}^{2} f^{\prime \prime}(x)+\frac{1}{6} \delta_{2}^{3} f^{\prime \prime \prime}(x)+\frac{1}{24} \delta_{2}^{4} f^{\prime \prime \prime \prime}(x)+\ldots
\end{aligned}
$$

Eq. (19) was obtained by multiplying Eq. (18) by $\delta_{1}{ }^{3} / \delta_{2}^{3}$ and subtracting Eq. (17) from it.

$$
\begin{aligned}
& f\left(x-\delta_{1}\right)+\frac{\delta_{1}^{3}}{\delta_{2}^{3}} f\left(x+\delta_{2}\right)=\left(1+\frac{\delta_{1}^{3}}{\delta_{2}^{3}}\right) f(x)+\left(\frac{\delta_{1}^{3}}{\delta_{2}^{2}}-\delta_{1}\right) f^{\prime}(x)+\frac{1}{2}\left(\delta_{1}^{2}+\frac{\delta_{1}^{3}}{\delta_{2}}\right) f^{\prime \prime}(x) \\
& +\frac{1}{24}\left(h_{1}^{4}+h_{1}^{3} h_{2}\right) f^{\prime \prime \prime \prime}(x)+\ldots
\end{aligned}
$$

Eq. (16) was then substituted into Eq. (19)

$$
\begin{aligned}
& f\left(x-\delta_{1}\right)+\frac{\delta_{1}^{3}}{\delta_{2}^{3}} f\left(x+\delta_{2}\right)=\left(1+\frac{\delta_{1}^{3}}{\delta_{2}^{3}}\right) f(x)+\left(\frac{\delta_{1}^{3}}{\delta_{2}^{2}}-\delta_{1}\right) \frac{f\left(x+\delta_{2}\right)-f\left(x-\delta_{1}\right)}{\delta_{2}+\delta_{1}} \\
& +\frac{1}{2}\left(\delta_{1}^{2}+\frac{\delta_{1}^{3}}{\delta_{2}}\right) f^{\prime \prime}(x)+\frac{1}{24}\left(\delta_{1}^{4}+\delta_{1}^{3} \delta_{2}\right) f^{\prime \prime \prime \prime}(x)+\ldots
\end{aligned}
$$

Finally the above expression was re-arranged to supply an expression for the second derivative of $f(x)$.

$$
f^{\prime \prime}(x)=\frac{\left(1+\frac{\frac{\delta_{1}^{3}}{\delta_{2}^{2}}-\delta_{1}}{\delta_{2}+\delta_{1}}\right) f\left(x-\delta_{1}\right)-\left(1+\frac{\delta_{1}^{3}}{\delta_{2}^{3}}\right) f(x)+\left(\frac{\delta_{1}^{3}}{\delta_{2}^{3}}-\frac{\frac{\delta_{1}^{3}}{\delta_{2}^{2}}-\delta_{1}}{\delta_{2}+\delta_{1}}\right) f\left(x+\delta_{2}\right)}{\frac{1}{2}\left(\delta_{1}^{2}+\frac{\delta_{1}^{3}}{\delta_{2}}\right)}+O(\delta)
$$

If the discretization is uniform then the order of accuracy of Eq. 20 is $O\left(\delta^{2}\right)$. In the application of the heat transfer model described in this paper $\delta_{1}$ and $\delta_{2}$ are defined as:

$$
\delta_{1}=x_{j}-x_{j-1}, \quad \delta_{2}=x_{j+1}-x_{j}
$$

where $j$ is the index of the current node. 


\section{Appendix B: Temperature vs. Time for Various Potential Mounting Locations}

This section provides temperature vs. time plots of various potential mounting locations near some of the major engine stations. Indicated in the legend is the exact location of the potential site. The data could prove useful in temperature cycling analysis as well as provide and idea of the complete temperature range the electronics will be exposed too.

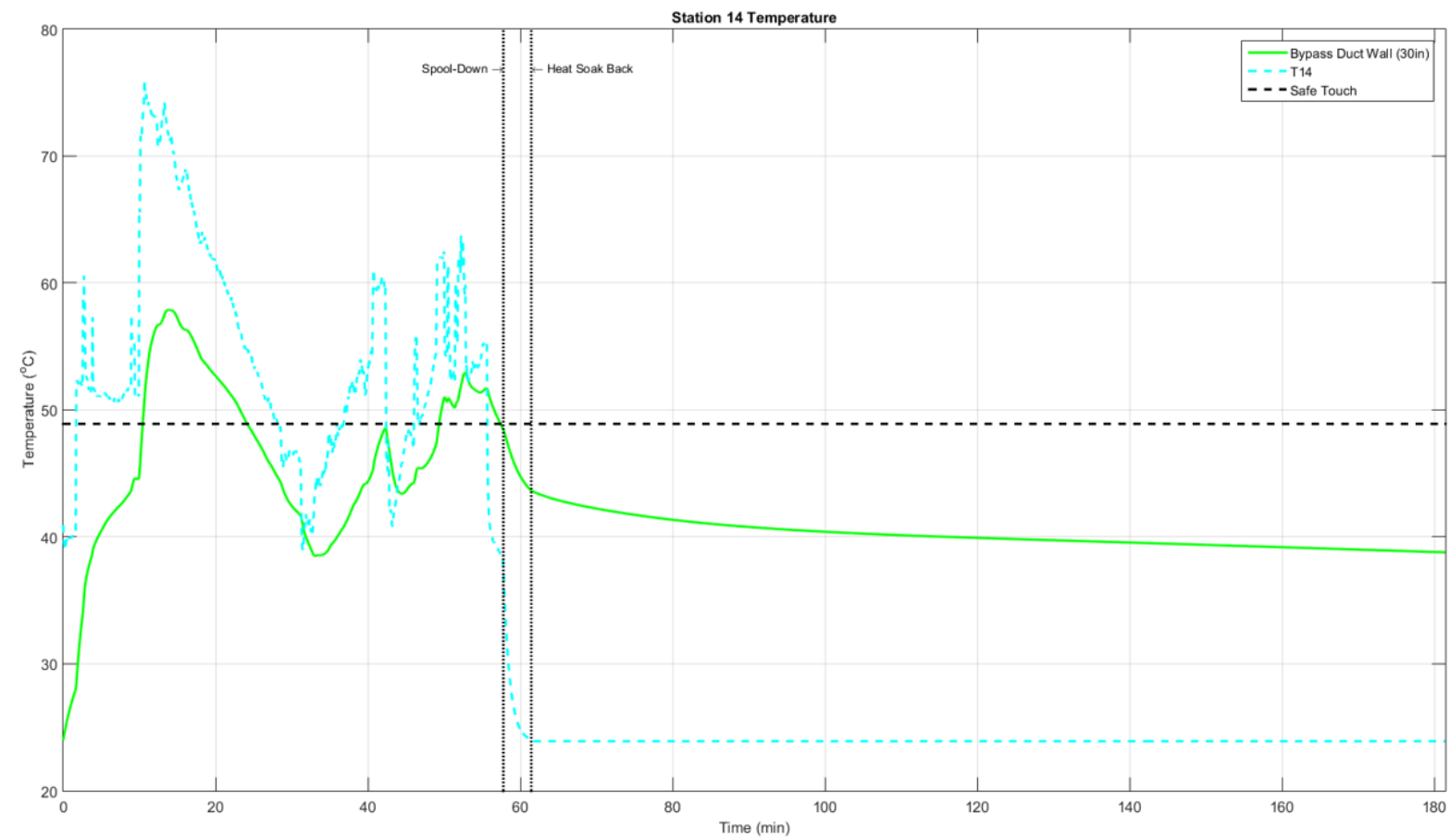

Figure 11. Temperature vs. time plot of potential electronics mounting locations for station 14

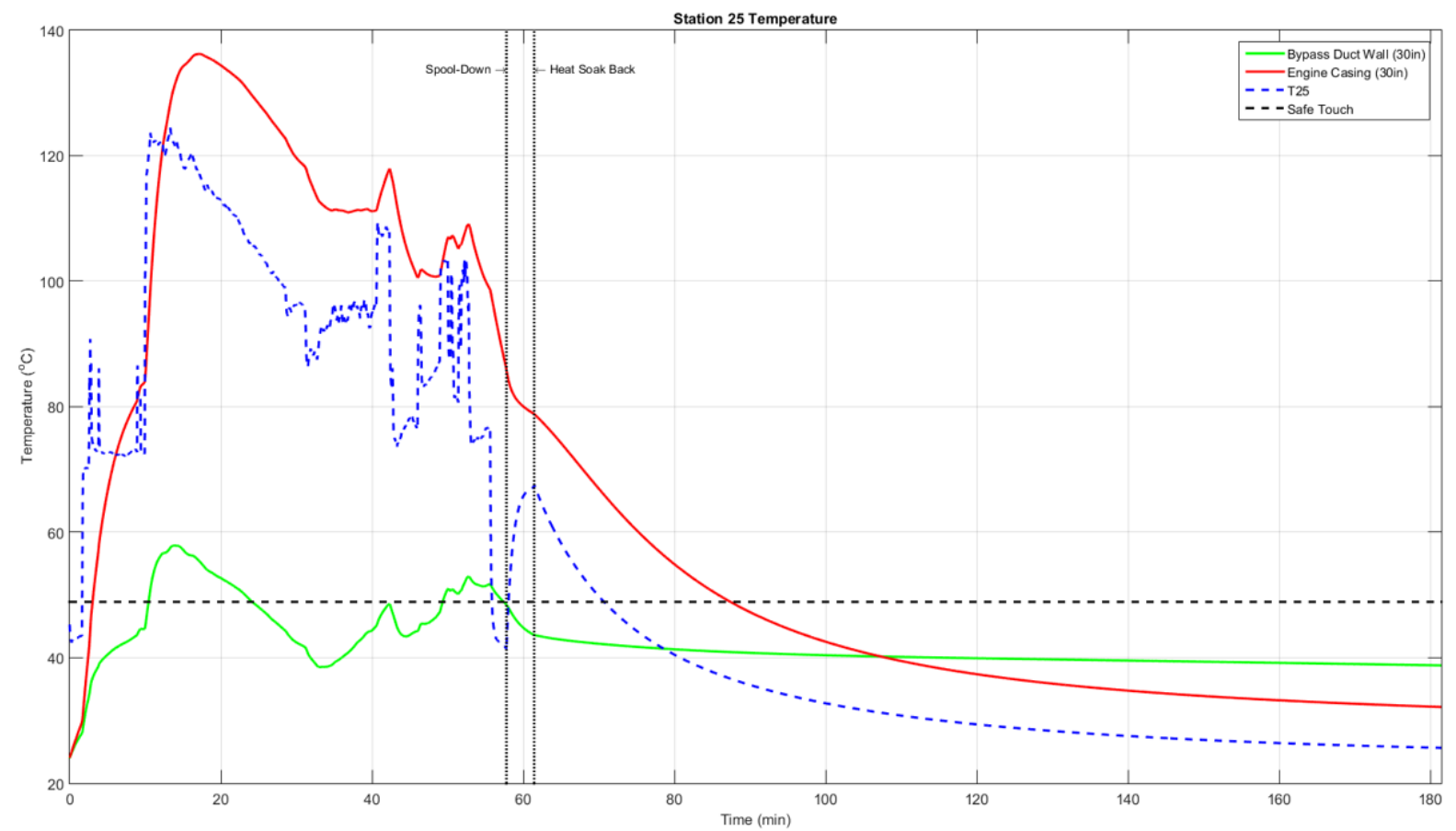

Figure 12. Temperature vs. time plot of potential electronics mounting locations for station 25

17

American Institute of Aeronautics and Astronautics 


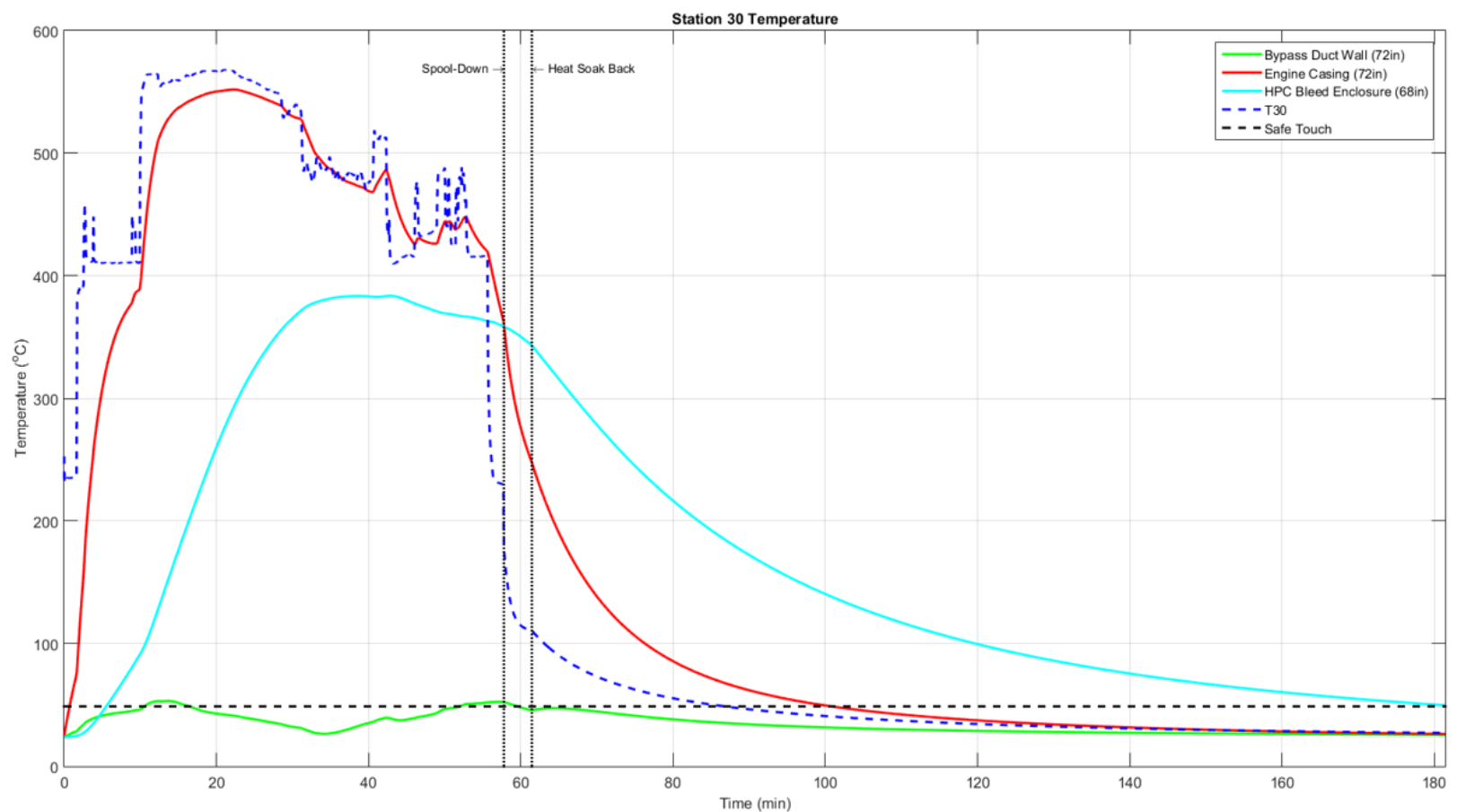

Figure 13. Temperature vs. time plot of potential electronics mounting locations for station 30

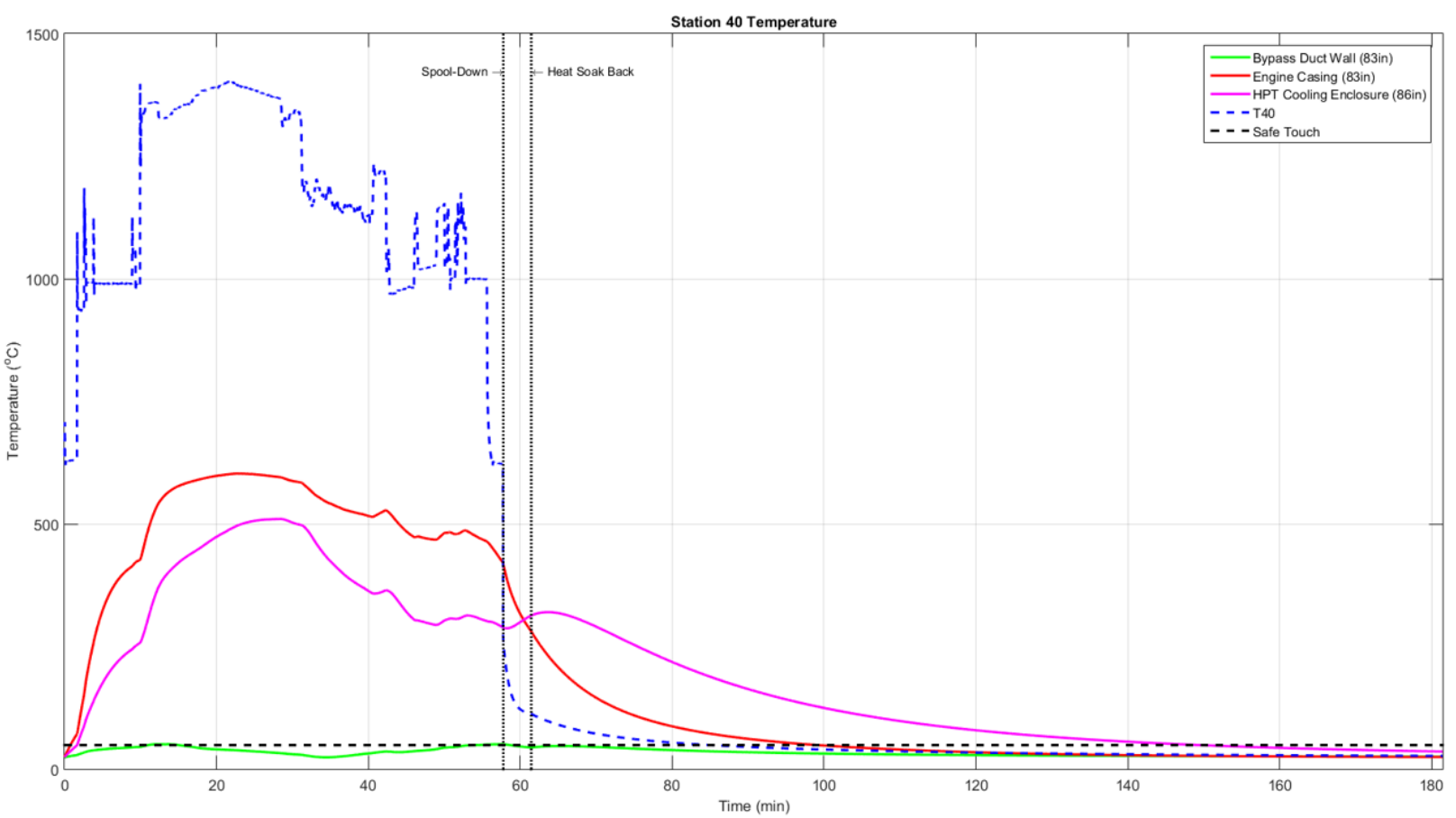

Figure 14. Temperature vs. time plot of potential electronics mounting locations for station 40 


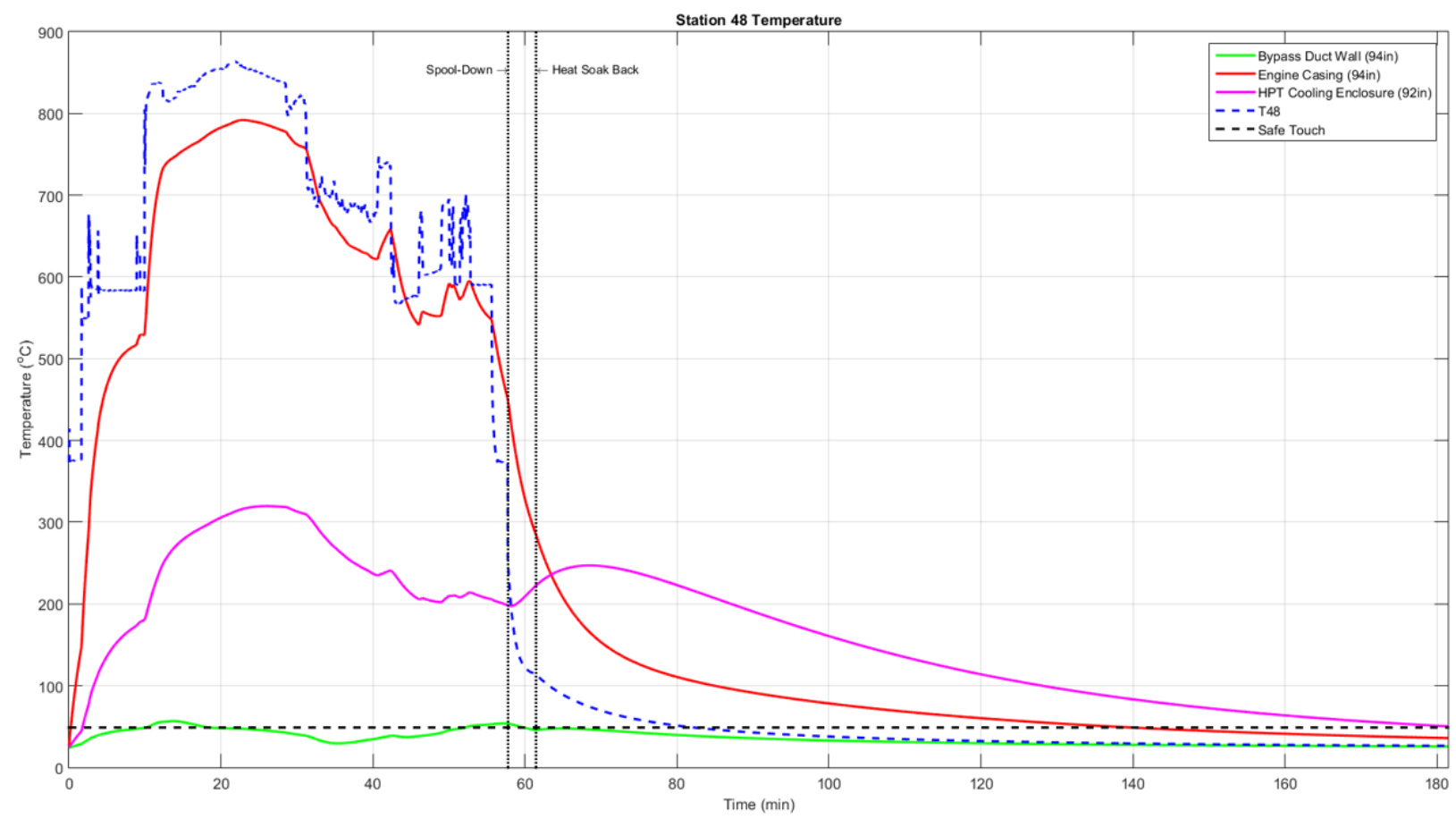

Figure 15. Temperature vs. time plot of potential electronics mounting locations for station $\mathbf{4 8}$

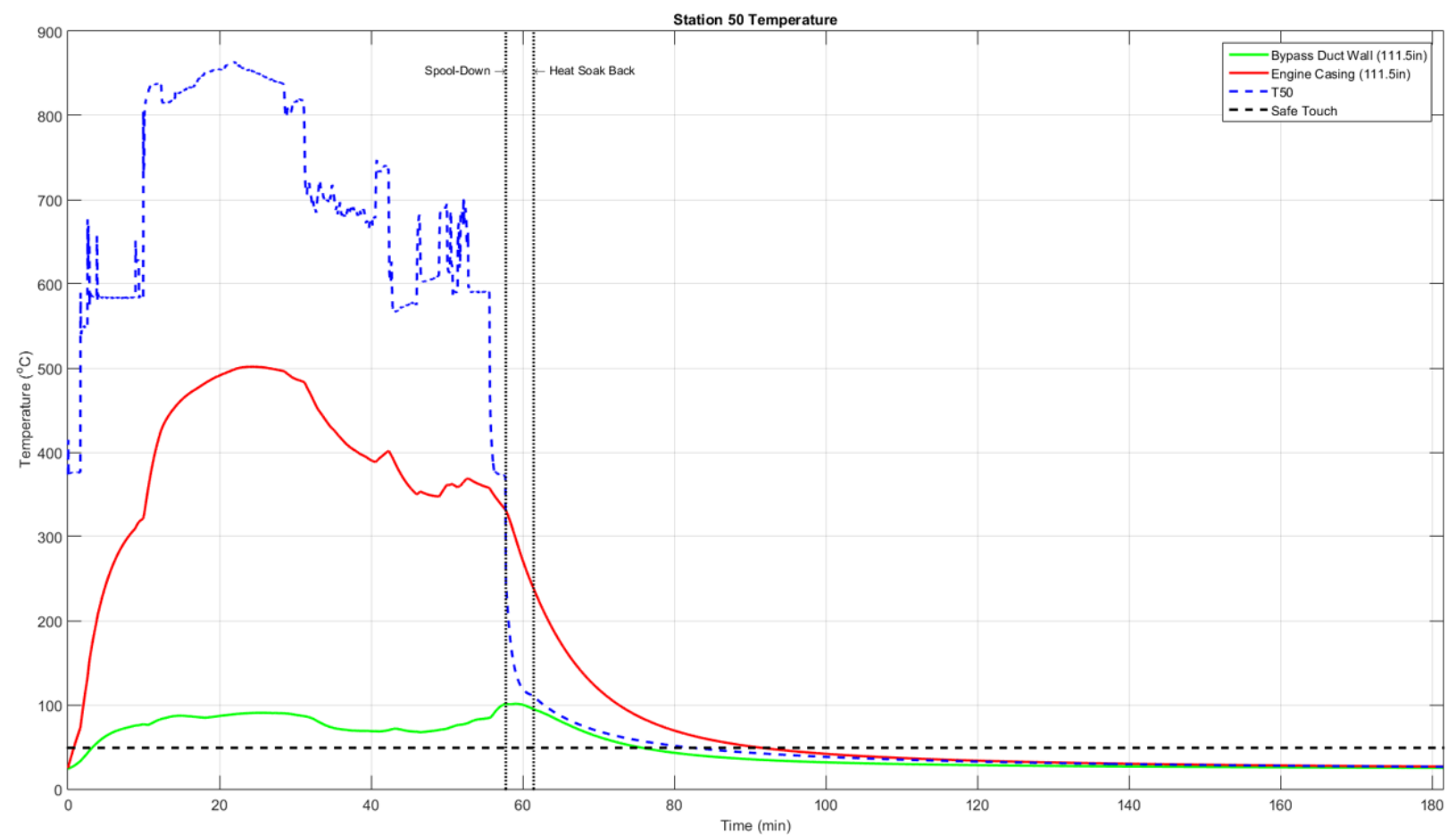

Figure 16. Temperature vs. time plot of potential electronics mounting locations for station 50 


\section{Appendix C: In-Flight Temperature Margin Analysis}
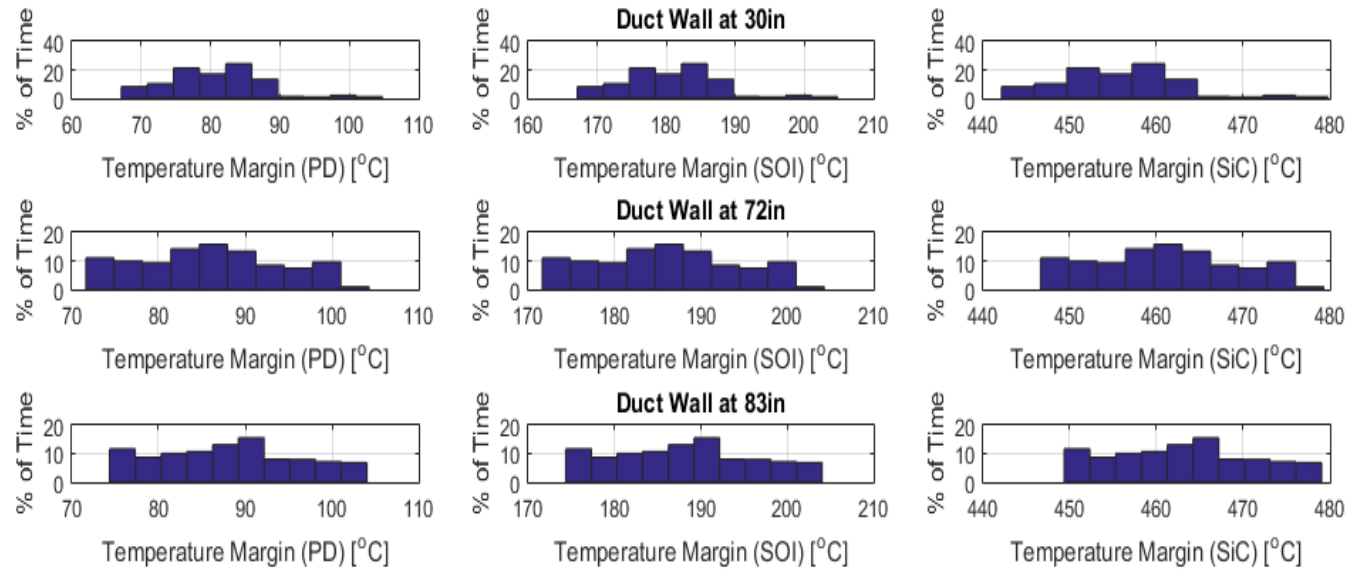

Temperature Margin (SOI) [ $\left.{ }^{\circ} \mathrm{C}\right]$
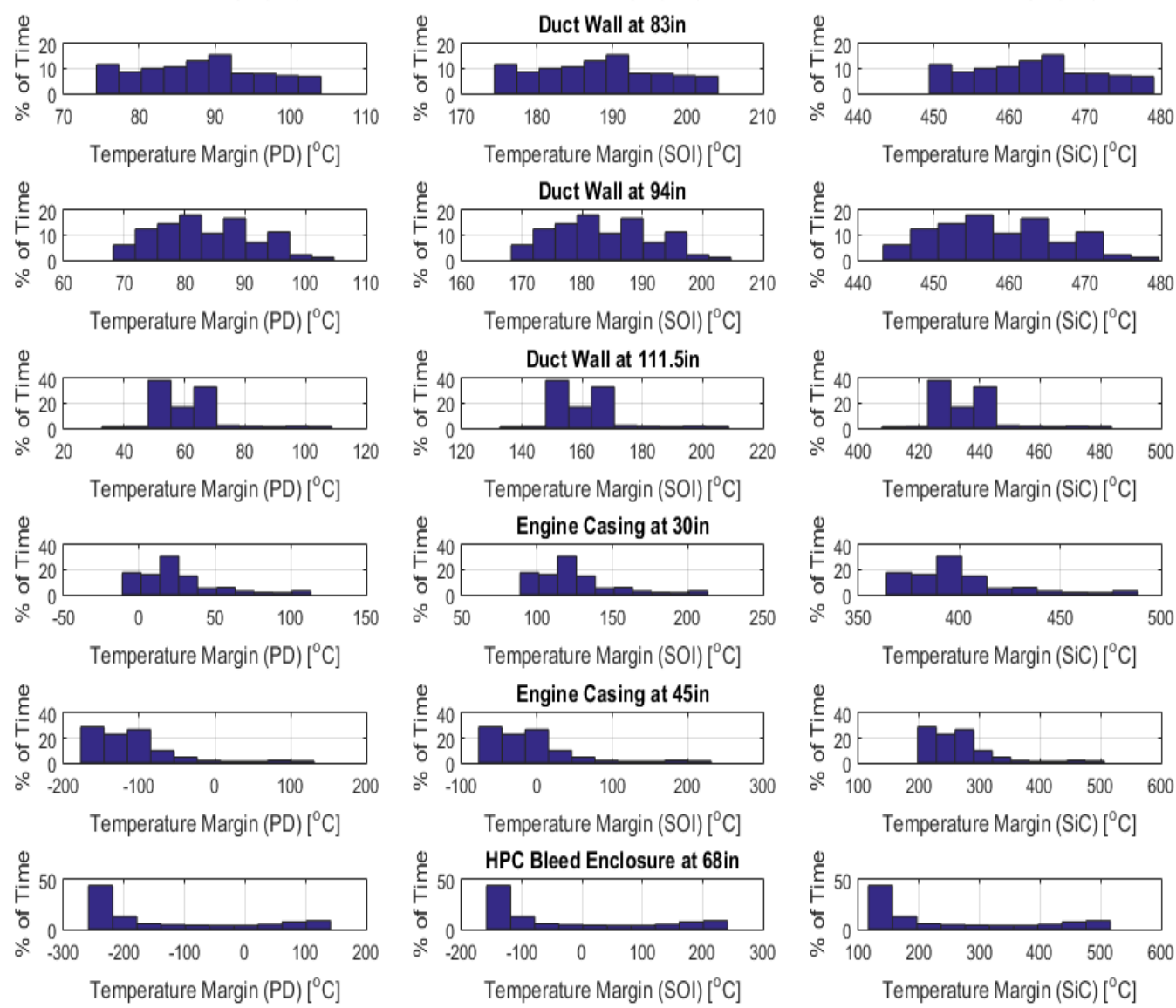

Figure 17. Temperature margin histogram for various potential mounting locations with margins based on the capabilities of present day (PD) electronics, silicon-on-insulator (SOI), and silicon carbide (SiC) capabilities of reliable operation which are and are expected to be $125^{\circ} \mathrm{C}, 225^{\circ} \mathrm{C}$, and $500^{\circ} \mathrm{C}$ respectively. 

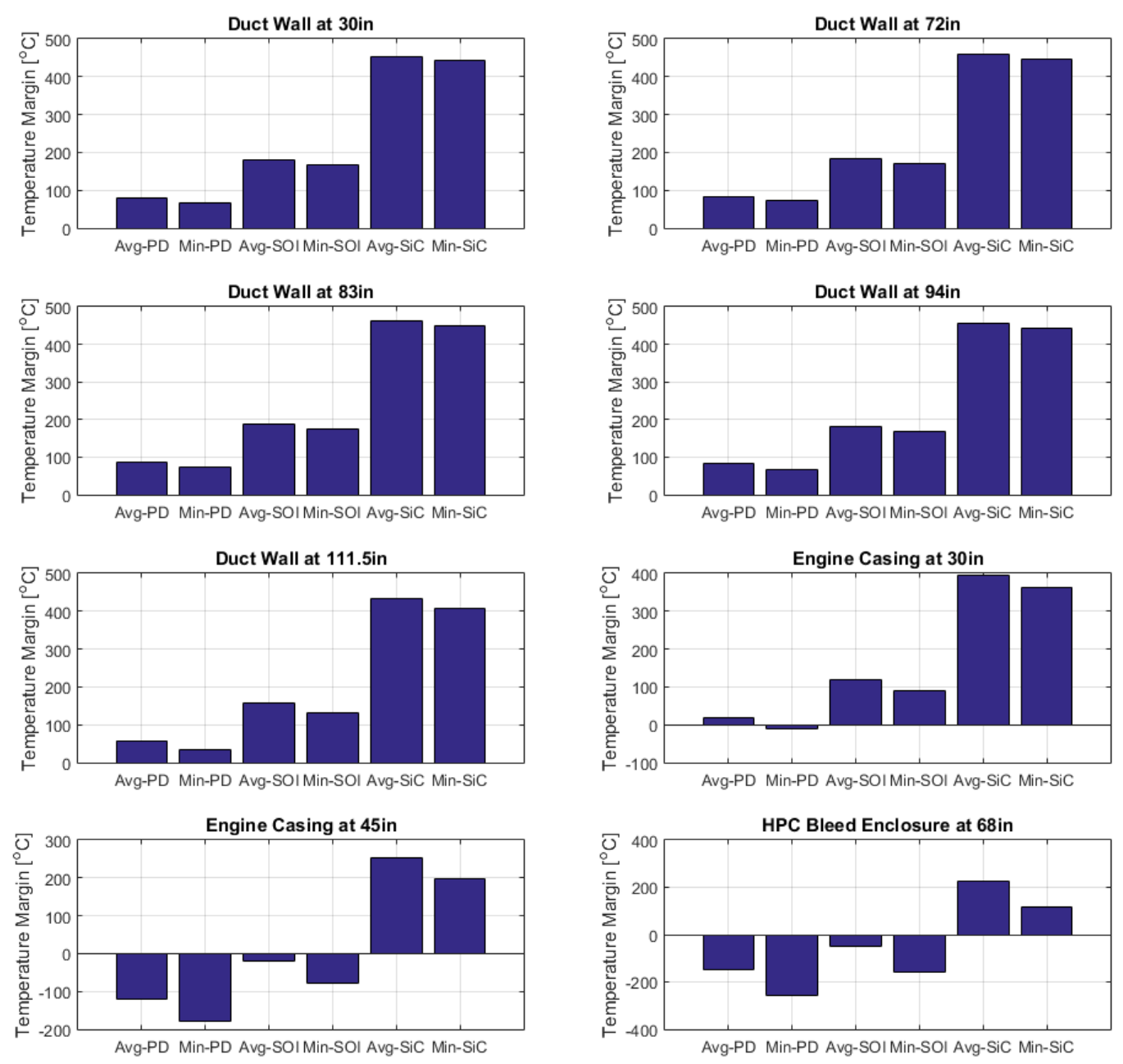

Figure 18. Average and minium temperature margins for various potential mounting locations relative to the capabilties of present day (PD), silicon-on-insulator ( $\mathrm{SOI}$ ), and silicon carbide (SiC) electronics with assumed capabilities of reliably operating at temperature of $125^{\circ} \mathrm{C}, 225^{\circ} \mathrm{C}$, and $500^{\circ} \mathrm{C}$ respectively. 

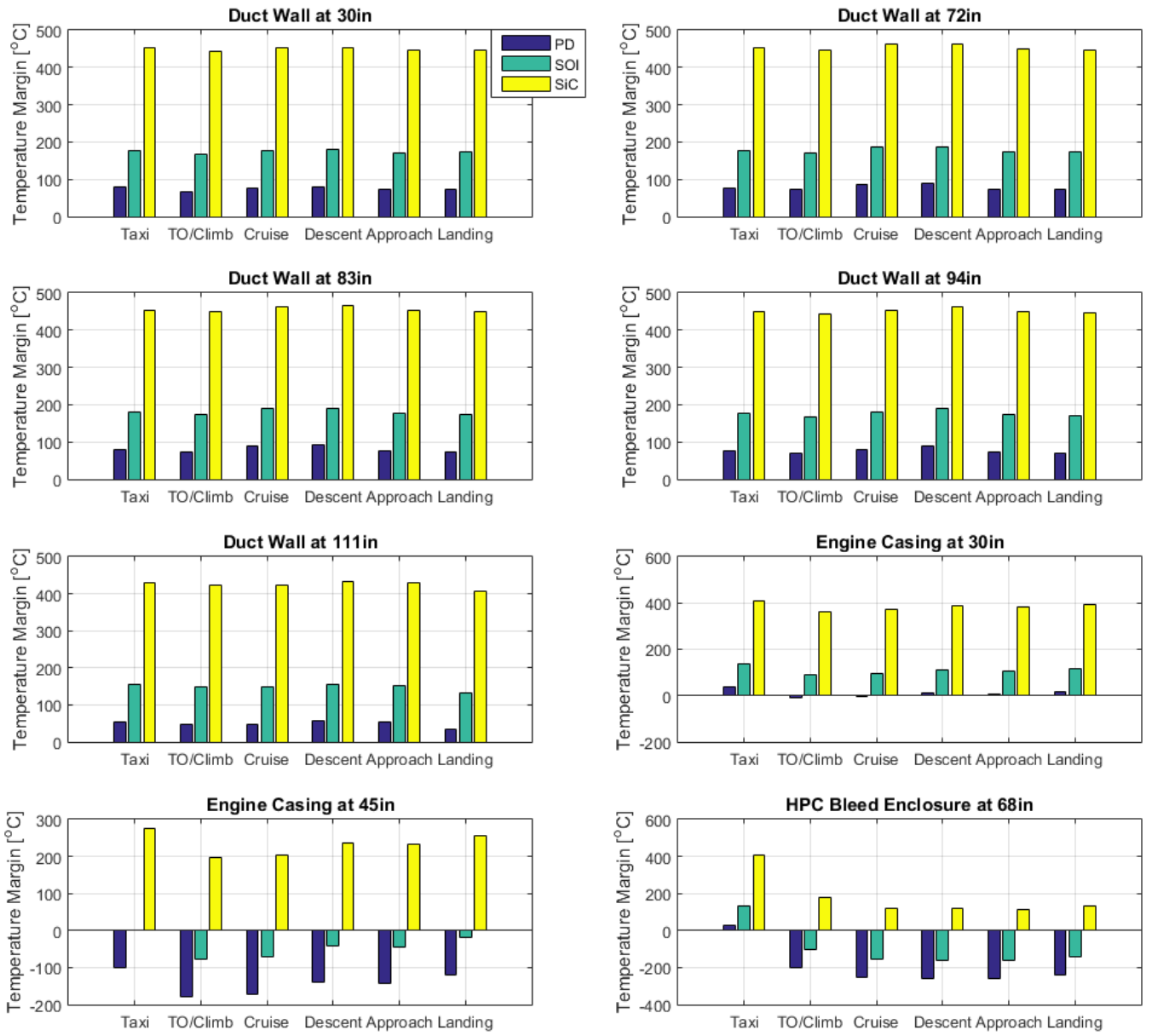

Figure 19. Minium temperature margins at various potential mounting locations for various phases of a typical commercial aircraft mission profile. The margins are based on the assumed capabilties of present day (PD), silicon-on-insulator (SOI), and silicon carbide (SiC) electronics which are $125^{\circ} \mathrm{C}, 225^{\circ} \mathrm{C}$, and $500^{\circ} \mathrm{C}$ respectively.

\section{Acknowledgments}

The authors would like to acknowledge the creators of C-MAPSS40k. Acknowledgment is also deserved by the Transformational Tools and Technologies (TTT) project at the NASA Glenn Research Center as part of the Aerospace Research Mission Directorate (ARMD). A special thanks goes to all those who provided information, guidance, and feedback on simulation profiles for C-MAPSS40k, engine geometry, and the engine casing heat transfer model during its development. This includes Don Simon, Roger Meredith, Jeff Csank, and Jonathan Litt from NASA Glenn Research Center and members of the Distributed Engine Controls Working Group (DECWG) including Bruce Wood from Pratt \& Whitney, and Jay Kokas, Ed Dodd and Bill Rhoden from United Technologies Aerospace Systems (UTAS). Finally the authors would like to extend their gratitude to Dan Paxson of the NASA Glenn Research Center whose comments helped to improve the dissemation of information through this paper. 


\section{References}

${ }^{1}$ Culley, D., Thomas, R., and Saus, J., “Concepts for Distributed Engine Control,” NASA TM-214994, 2007.

${ }^{2}$ Culley, D., Paluszewski, P., Storey, W., and Smith B., "The Case for Distributed Engine Control in Turbo-Shaft Engine Systems," NASA TM-215654, 2009

${ }^{3}$ Behbahani, A., Wood, B., Benson, D., Berner, A., Hegwood, B., Dejager, J., Rhoden, W., Ohme, B., Sloat, J., and Harmon, C., "Technology Requirements and Development for Affordable High-Temperature Distributed Engine Control," Proceeding of the $58^{\text {th }}$ International Instrumentation Symposium, San Diego, CA, 2012

${ }^{4}$ Belapurkar, R., "Stability and Performance of Propulsion Control Systems with Distributed Control Architectures and Failures," Ph.D. Dissertation, Aeronautics and Astronautics Dept., The Ohio State Univeristy, Columbus, Ohio, 2012.

${ }_{5}^{5}$ Behbahani, A., Culley, D., Carpenter, S., Mailander, B., Hegwood, B., Smith, B., Darouse, C., Mahoney, T., Quinn, R., Battestin, G., Roney, W., Millar, R., Bluish, C., Rhoden, W., Wood, B., Krodel, J., Storey, B., "Status, Vision, and Challenges of an Intelligent Distributed Engine Control Architecture", Proceedings of the 2007 SAE Aero Tech Congress \& Exhibition, Los Angeles, CA, 2007

${ }^{6}$ Halbig, M., Brewer, D., and Eckel, A., "Degradation of Continuous Fiber Ceramic Matrix Composites Under Constant-Load Conditons," NASA TM-209681, 2000

${ }^{7}$ Mallison, E.R., Rogers, J.D., and Ohme, B., High Temperature SOI CMOS Electronics Development.

${ }^{8}$ Hunter, G., Okojie, R., Neudeck, P., Beheim, G., Ponchak, G., Fralick, G., Wrbanek, J., and Chen, L. "High Temperature Electronics, Communications, and Supporting Technologies For Venus Missions," Electrical and Electronic Engineering (2006), pp. $27-30$

${ }^{9}$ Hunter, G., Beheim G., Ponchak, G., Schardelletti, M., and Meredith, R., "Development of High Temperature Wireless Sensor Technology Based on Silicon Carbide Electronics," The Electrochemical Society, 2010

${ }^{10}$ Usrey, M., Liu, Y., Schaible, B., Harsh, K., Behbahani, A., "High-Temperature Sensor and Electronics Packaging Technologies for Distributed Engine Controls," Proceeding of the 50 ${ }^{\text {th }}$ AIAA/ASME/SAE/ASEE Joint Propulsion Conference, Cleveland, $\mathrm{OH}, 2014$

${ }^{11}$ Evans, L., Okojie, R., and Lukco, D. "Development of an Extreme High Temperature n-type Ohmic Contact to Silicon Carbide," Materials Science Forum, vol. 717-720, pp. 841-844 @ Trans Tech Publications

${ }^{12}$ David J. Spry, Philip G. Neudeck, Liangyu Chen, Dorothy Lukco, Carl W. Chang, Glenn M. Beheim, Michael J. Krasowski, and Norman F. Prokop, "Processing and Prolonged $500{ }^{\circ} \mathrm{C}$ Testing of $4 \mathrm{H}-\mathrm{SiC}$ JFET Integrated Circuits with Two Levels of Metal Interconnect", to appear in Silicon Carbide and Related Materials 2015, Materials Science Forum, Trans Tech Publications, Switzerland, 2016

${ }^{13}$ Babu C.R., "Thermal Stress Analysis of a Gas Turbine Casing Using FEA," IOSR Journal of Mechanical and Civil Engineering, Vol. 11, Issue 4, Ver. III, pp. 32-37, 2014

${ }^{14}$ Mahulikar, S., "Prediction of Engine Casing Temperature of Fighter Aircraft for Infrared Signature Studies," SAE Technical Paper 920961, 1992.

${ }^{15}$ May, R., Csank, J., Lavelle, T., Litt, J., and Guo T.-H.K., “A High-Fidelity Simulation of a Generic Commercial Aircraft Engine and Controller", NASA TM-216810, 2010

16"Sample Flight Data." DASHlink -. Web. 17 Dec. 2015. https://c3.nasa.gov/dashlink/projects/85/resources/

${ }^{17}$ Daly, M., Jane's Aero Engines, Issue 28, Ed., Jane's Information Group, London, England, September 2010.

${ }^{18}$ Incropera, F.P., and DeWitt, D.P., Fundamentals of Heat and Mass Transfer, John Wiley \& Sons, New York, NY, 2002. Print.

${ }^{19}$ Anderson, J.D., Computational Fluid Dynamics: The Basics with Applications, New York: McGraw-Hill, 1995. Print.

${ }^{20}$ Lemmon, E., Jacobsen, R., Penoncello, S., and Friend, D., "Thermodynamic Properties of Air and Mixtures of Nitrogen, Argon, and Oxygen From 60 to 2000K at pressure to 2000MPa," Journal of Physics Chemistry Reference Data, Vol. 29, No. 3, 2000 .

${ }^{21}$ Lemmon, E., and Jacobsen, R., "Viscosity and Thermal Conductivity Equations for Nitrogen, Oxygen, Argon, and Air," International Journal of Thermophysics, Vol. 25, No. 1, January 2004.

${ }^{22}$ Churchill S.S., Chu H.H.S., "Correlating equations for laminar and turbulent free convection from a horizontal cylinder," International Journal of Heat and Mass Transfer Vol. 18, pp.1049-1053, 1975

${ }^{23}$ Raithby, G.D., and Hollands, K.G.T., "A General Method of Obtaining Approximate Solutions to Laminar and Turbulent Free Convection Problems," Irvine, T.F., and Hartnett, J.P., Eds., Advances in Heat Transfer, Vol. 11, pp. 265-315, Academic Press, New York, NY. 1975.

${ }^{24}$ Svensdotter, S., Skelton, L., and Ingle, J., "Shutdown Modeling to Extend Engine Operation to Extreme Ambient Conditions," Proceedings of the 2007ASME Turbo Expo: Power for Land, Sea and Air Conference, Montreal, Canada, 2007. 